\title{
Engineering Radical Polymer Electrodes for Electrochemical Energy Storage
}

\author{
Douglas R. Nevers ${ }^{\mathrm{a}}$, Fikile R. Brushett ${ }^{\mathrm{b}}$, Dean R. Wheeler ${ }^{\mathrm{a}, *}$ \\ ${ }^{a}$ Department of Chemical Engineering, Brigham Young University, 350 CB, Provo, Utah 84602 USA \\ ${ }^{b}$ Department of Chemical Engineering, Massachusetts Institute of Technology, 77 Massachusetts Avenue \\ Cambridge, MA 02139 USA
}

\begin{abstract}
In principle a wide range of organic materials can store energy in the form of reversible redox conversions of stable radicals. Such chemistry holds great promise for energy storage applications due to high theoretical capacities, high rate capabilities, intrinsic structural tunability, and the possibility of low-cost "green" syntheses from renewable sources. There have been steady improvements in the design of organic radical polymers, in which radicals are incorporated into the backbone and/or as pendant groups. This review highlights opportunities for improved redox molecule and polymer design along with the key challenges (e.g., transport phenomena, solubility, and reaction mechanisms) to transitioning known organic radicals into high-performance electrodes. Ultimately, organic-based batteries are still a nascent field with many open questions. Further advances in molecular design, electrode engineering, and device architecture will be required for these systems to reach their full potential and meet the diverse and increasing demands for energy storage.
\end{abstract}

Keywords:

Electrochemical energy storage, organic battery, radical polymer, conducting polymer, redox flow battery, electrode

\section{Introduction}

Realizing the potential of electrochemical energy storage for renewable and distributed energy uses (e.g., wearable devices and networks of autonomous smart devices) will require drastic improvements of current state-of-the-art systems [1,2]. Present storage options have not yet achieved the necessary combination of technical performance, cost, and safety needed to compete with non-renewable or less environmentally friendly alternatives [3-9]. Recently, researchers have begun to explore the use of stable organic radicals, both discrete molecules and radical-bearing polymers, as redox-active materials for electrochemical energy storage [10-19]. Here, the term stable organic

*Corresponding author

Email address: dean_wheelerabyu . edu (Dean R. Wheeler)

Preprint submitted to Elsevier

February 25, 2017

(C) 2016. This manuscript version is made available under the Elsevier user license http://www.elsevier.com/open-access/userlicense/1.0/ 
radical is used to describe a molecule which undergoes reversible single (or multiple) electron transfer(s) without decomposition or irreversible reaction with another species in either its charged or neutral state. In some cases, these stable radical compounds are already well-studied for other purposes, such as dye indicators, spin-labeling molecules, catalysts, and redox shuttles in Li-ion batteries for overcharge protection [20, 21].

As compared to more traditional inorganic charge storage materials, such as metals, metalloids, and metal oxides, redox-active organic radicals have tantalizing potential advantages for a range of electrochemical energy storage applications including lower cost, high intrinsic capacity, structural tunability, high power capabilities, and long lifetimes. Moreover, in terms of lifecycle, organic materials are based on abundant elements (e.g., $\mathrm{C}, \mathrm{O}, \mathrm{N}, \mathrm{S})$ and feedstocks $\left(e . g ., \mathrm{CO}_{2}\right)$, which may be synthesized via green chemistry routes, and cost-effectively recycled [22-25]. It should be noted that commercial viability has not yet been demonstrated for an all-organic battery, and considerable work would be needed to turn synthesis of the required specialty chemicals into a low-cost commodity process. Nevertheless, these advantages make organicbased rechargeable batteries a potentially transformational storage concept for grid and transportation applications-the two largest electricity consumption sectors. Similar benefits could accrue for smaller-scale portable electronics and wearable devices, with the additional benefits of increased geometric flexibility and conformability [26]. In the near term, organic molecules can be used as additives in traditional Li-ion batteries as redox shuttles or conductive additives/binders [27-29]. Overall, organic radical batteries could significantly impact and improve energy storage at all scales.

A range of organic materials have been investigated for energy storage applications including carbonyls (e.g., quinones [30-36], polyketones [37, 38], indigo dye [39], imides [40-42], carboxylates [12, 43-45], and anhydrides [46]), organosulfur compounds [47-49], and stable radicals [50-54]. Figure 1 summarizes the general ranges of key battery performance metrics for the three main chemistries: organosulfur, radical, and carbonyl compounds [11]. This illustration highlights a few of the advantages and disadvantages of each class. Organosulfur compounds have the highest capacities, but poor cyclability and sluggish redox kinetics. Radical compounds have higher power capabilities (10-80 C-rate where a C-rate of 1 is full discharge in $1 \mathrm{~h}$ ), high redox potentials, and good tunability, but the lowest capacities. Carbonyl-based compounds have higher theoretical capacities, but are a relatively untested chemistry.

The field of organic radical-based batteries is emergent. Of the references herein, roughly 50 were published between 1996 and 2006. In the most recent decade (20062016), that number increased four-fold to over 200 papers. We broadly divide organic radicals for energy storage into discrete (small or non-polymeric) molecules and organic radical polymers. Discrete organic molecules have been comprehensively reviewed [11, 55-58]. Other recent reviews have discussed radical polymer synthesis [59-61], general advantages and disadvantages of organic battery chemistries $[11,17,56]$, and their application in organic electronic devices [62]. Notably, there is significant overlap between small molecules and radical polymers as many known small molecules have been immobilized on polymer backbones to prevent dissolution issues, albeit at the expense of gravimetric capacity [10, 59, 63, 64].

This review aims to outline notable advances and critical challenges to the translation of known organic radical polymers into the high-performance electrodes necessary 

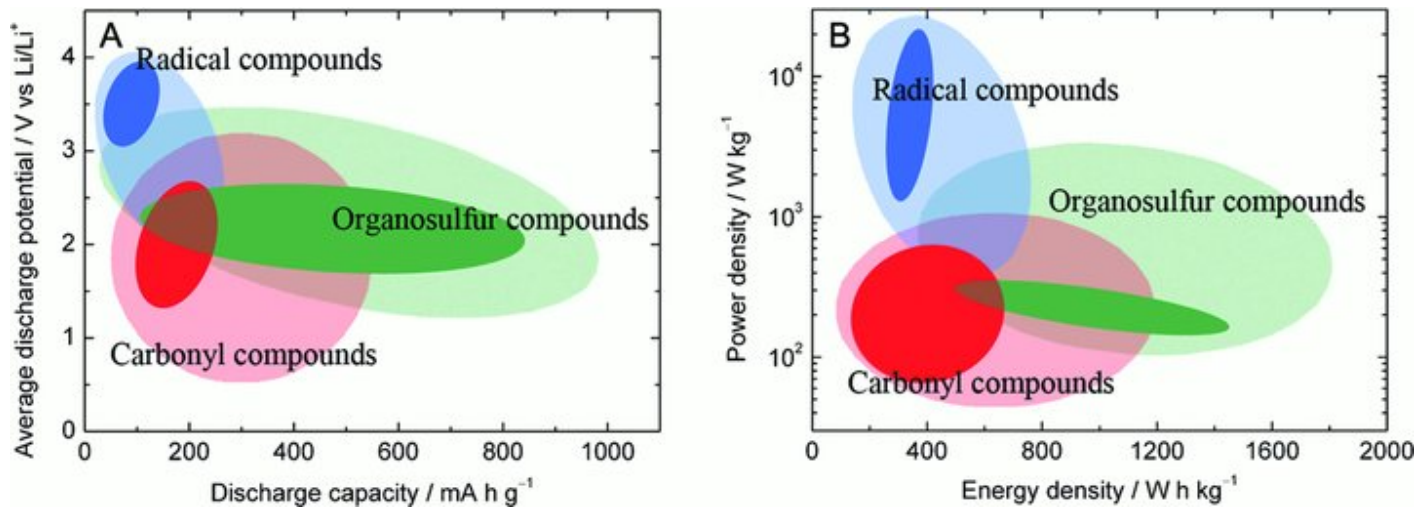

Figure 1: Graphical comparison of the cell performance of organosulfur (green), radical (blue), and carbonyl compounds (red) in the form of potential vs. capacity (A) and power density vs. energy density (B). The regions marked with deep shades cover the most typical values reported in the literature, while those with light shades represent achievable values for the specific class of compounds. Reprinted with permission from ref. [11]. Copyright 2012 John Wiley and Sons.

for enabling applications. Specifically, this review focuses on the design of polymer electrodes and the control of underlying transport phenomena in order to overcome present challenges, namely low energy density, low intra-electrode conductivity, and capacity loss. This review is organized as follows. Section 2 discusses chemical design, which sets the theoretical limit of a radical polymer's performance. The next two sections evaluate detailed approaches to achieve these theoretical limits based on electrode design. Section 3 discusses bulk-property or macroscopic electrode design (such as electrode composition and thickness) while Section 4 considers microstructure electrode design (such as electronic and ionic conductive networks, kinetic processes, and binding methods). Finally, Section 5 examines recent applications of radical polymers in batteries.

\section{Radical chemistry}

\subsection{Organic radicals}

Over the past century, numerous electroactive organic molecules have been cataloged [65-67], but comparatively few families have demonstrated suitable performance to warrant consideration for energy storage applications. Several recent comprehensive reviews have described the application of redox-active organics as electrode materials and/or as performance additives in advanced rechargeable batteries [11, 23, 55, 57, 58, $68,69]$.

A radical is a subvalent compound with an unpaired electron, which is typically extremely reactive and, consequently, short lived. However, since Gomberg's synthesis of triphenylmethyl (trityl) radical in 1900, numerous families of persistent and stable radicals have been identified and have been the subject of reviews and books $[18,20,66$, 67]. In general, radical stability arises from steric protection of the radical center, via the 
addition of bulky substituents, and/or delocalization of the unpaired electron throughout the molecular structure [20,70-75]. Prominent and promising classes of stable organic radicals for energy storage include nitroxides [50, 67, 76, 77], phenoxyls [13, 20, 51$53,78-81]$, and verdazyls [54, 82]. Notably, many of these radical families have been used as redox-active pendants in radical polymers to leverage their electro-activity and minimize loss due to dissolution into the electrolyte [10, 59, 63, 64].

In electroactive polymer materials, the polymer backbone, the pendant group, or both may be used for charge storage in battery electrodes. In general, three categories of organic radical polymers have been investigated for energy storage applications: conducting, radical-bearing, and radical-bearing conducting polymers.

\subsection{Conducting polymers}

Conducting polymers comprise a vast field, with numerous applications ranging from antistatic coatings and displays to supercapacitors and batteries [83-86]. An attractive feature of these materials is the flexibility of organic synthesis and processing with the possibility for achieving metal-like electrical conductivity. A few of the most common conducting polymers include polyaniline, polyacetylene, polythiophene, polypyrrole, and poly(3,4-ethylenedioxythiophene) (PEDOT) [87, 88] (see Figure 2a). This field has been extensively reviewed and thus is only briefly treated here [83-86, 89-91].

While the exact conduction mechanism of conducting polymers is still under debate (see Heinze et al. for details [90]), the classical model is a series of redox reactions in which electrons effectively hop along the polymer backbone from redox site to redox site with the aid of delocalized electrons [101, 102]. Both intra- and inter-chain hopping modes are sensitive to the conformation and arrangement of the polymer chains [90, 101, 103-105]. The hopping also depends on the number of charges (or radicals) on the backbone or doping level (charges/monomer unit). For instance, the conductivity of 3-methylthiophene increases by $10^{8}$ times when oxidized to a 35\% doping level (neutral conductivity: $10^{-6} \mathrm{~S} / \mathrm{cm}$, see Table $\mathrm{S} 1$ for conductivities of other conducting polymers) [91, 106]. Furthermore, the open circuit voltage and consequently energy density of 3-methylthiophene increases with doping level (open circuit voltage: 2.5 to $4.0 \mathrm{vs}$. $\mathrm{Li} / \mathrm{Li}^{+}$with 0 to $35 \%$ doping; at $35 \%$ doping level, the specific energy was $326 \mathrm{Wh} /(\mathrm{kg}$ active material)) [106]. Thus, as a battery discharges, the doping level and voltage decline continuously along with the conductivity [32, 88, 106-111].

In terms of electrochemical energy storage, conducting polymers offer high charge density and low cost along with their namesake conductivity [112-114]. Conducting polymers have been used as the conductive additive of Li-ion battery electrodes (e.g., $\mathrm{LiFePO}_{4}$ ) and enable high capacities to be achieved without other carbon or binder $[27,115,116]$. Nevertheless, pressing challenges have limited their adoption as the active charge storage material in batteries including low achievable current densities (attributed to slow transport and kinetics of doping/undoping processes), short cycle life, low Coulombic efficiency (ratio of charge output to charge input), and lack of a constant discharge voltage (or flatness in the discharge curve) [83, 91]. Low current densities (or slow charge/discharge rates) are a particular hindrance to applications in batteries [83]. 


\section{Conducting Polymers}

(a)<smiles>CC(C)(C)/C=C/C=C/C(C)(C)C</smiles>

(d)<smiles>Cc1ccc(C)[nH]1</smiles>

Radical Polymers

(g)

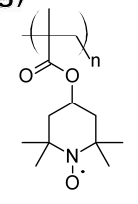

(k)

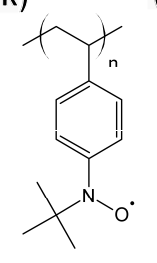

(h)

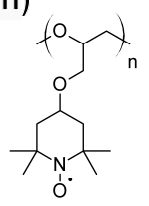

(I)

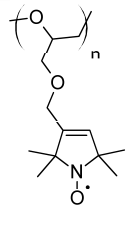

(e)<smiles>c1ccc2sccc2c1</smiles>

(i)<smiles>C=CC(C)OC1CC(C)(C)N(C)C1(C)C</smiles>

(m)

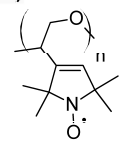

(c)

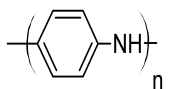

(f)

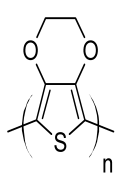

(j)

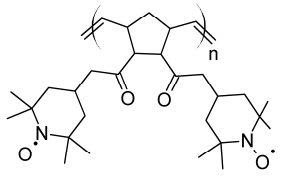

(n)

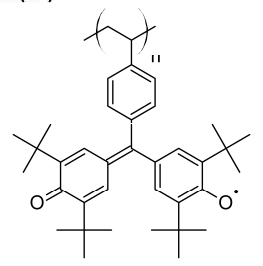

Figure 2: Repeating unit structures for various conducting polymers [83]: (a) Trans-poly(acetylene), (b) poly(pphenylene), (c) polyaniline, (d) polypyrrole, (e) polythiophene, (f) poly(3,4-ethylenedioxythiophene) (PEDOT), and for various radical polymers: (g) poly(TEMPO-methacrylate) [10], (h) poly(TEMPO-ether) [92], (i) poly(TEMPO-vinyl ether) [93-95], (j) poly(TEMPO-norbornene) [96, 97], (k) poly(nitroxylstyrene) [98], (l) poly(PROXYL ether) [92], (m) poly(PROXYL ethylene oxide) [99], and (n) poly(galvinoxylstyrene) [100]. 


\subsection{Radical-bearing polymers}

Compared to conducting polymers $(0.1-0.92$ charges per monomer) [91, 117], radical-bearing polymers have a consistently high doping level (0.8-0.9 radicals per monomer) for charge storage as the radical is covalently bonded to the polymer backbone rather than part of the backbone [63]. Other advantages of radical-bearing polymers include tunable physical and electrochemical properties, facile solution processing, environmentally-benign character, high power densities, and long cycle life. Notably, much of the prior work in the field of radical polymers concentrates on the use of stable radical polymers as cathode materials for Li-metal batteries [10, 11, 17, 23, 55].

Comparing battery performance of small-molecule-based electrodes to radicalpolymer electrodes highlights that radical-polymer-based batteries have higher power capabilities (10-80 C-rate) as well as higher and tunable redox potentials, but lower capacities (see Figure 1). Overall, achieving high specific energy is one of the key challenges limiting organic radical batteries, which are currently more like supercapacitors [118]. The focus on power density in organic radical battery research is likely a byproduct of the need for thin-film and low-loading designs. This must be rectified (see Sec. 3). Nevertheless, the theoretical specific energies of radical polymers are on par with those of typical Li-ion batteries (see Sec. 3.1), and radical polymer electrodes provide additional advantages that suggest particular and complementary applications to Li-ion batteries [59]. Such applications include flexible portable device (e.g., smart cards) or redox-active binders that both increase conductivity and reduce active species solubility [29] while complementary applications could include high-power applications (e.g., camera flash in cell phones or backup batteries) and other hybrid battery-capacitor systems [10, 119-121].

In terms of reaction mechanism, Oyaizu et al. showed that compact, or lowmolecular-weight, radical-bearing polymers provided smaller inter-site (or inter-radical) distances that facilitate rapid charge hopping. Charge hopping is part of the reaction propagation mechanism for charging and discharging radical polymer batteries [99, 122-124]. Notably, this hopping mechanism is similar to the electronic conduction mechanism for conducting polymers, indicating that radical pendants may facilitate electronic conductivity. (This concept is discussed in greater detail in Sec. 4.3.)

\subsubsection{Chemical tunability}

A key advantage of polymers and organic radicals is their wide variety and chemical tunability $[63,125]$. While a large number of polymer backbones have been investigated, only a few of the many possible radicals $[18,20]$ have been investigated as part of a radical polymer. In principle, any polymer could be used so long as the radical can be chemically attached without compromising its stability and redox reversibility $[61,87,108,126]$. To date, the following polymers have received the most attention: poly(methacrylate), poly(vinyl ether), poly(norbornene), poly(allene) (see Figure $2 b$ for structures). In terms of radical pendants, the most widely-studied stable radicals are those that are commercially available as spin-labels and spin-traps: TEMPO, PROXYL, iminoxyl, doxy-stearic acid, 2,2-Diphenyl-1-picrylhydrazyl (DPPH), and galvinoxyl [127]. Specifically, the nitroxide radical group, e.g. 2,2,6,6-tetramethyl-piperidin-1oxyl (TEMPO), has received the most attention because of its rapid redox kinetics 
and air-stability [128-130]. Further, chemical modification (e.g., structural orientation or substituent groups) can be used to maximize the redox potential or create p- or n-type radical polymers [98, 131-135]. (Note: radical polymers are assigned as p-type (positive) and n-type (negative) based on the recommended nomenclature.)

The substantial advantages of tunability must be counterbalanced by the large upfront expense of organic synthesis and reagents. Nevertheless, over time commercialization of organic radical batteries would decrease the material cost due to economies of scale similar to that for other polymers [136]. Additionally, organic materials offer facile solution processing (e.g., printing and roll-to-roll methods) that may speed their production scale-up and commercialization $[59,62,136]$.

\subsubsection{Electrochemical properties}

A wide range of redox potentials and theoretical capacities are accessible via different chemistries (See Table S2, shown in Figure 3a) [92, 99, 137-140]. The theoretical capacity is defined as $\mathrm{Fa} / \mathrm{F}_{w}$ where $F$ is the Faraday constant, $a$ is the number of charges that can be stored on a particular monomer, and $F_{w}$ is the formula weight of the monomer. Specifically, the theoretical capacity ranges from $30.7 \mathrm{Ah} / \mathrm{kg}$ for large monomer units such as poly(TEMPO-ethyl cellulose) to $134 \mathrm{Ah} / \mathrm{kg}$ for small units such as poly(TEMPO-vinyl ether) or $172 \mathrm{Ah} / \mathrm{kg}$ for units capable of multi-electron transfer such as di-radical poly(TEMPO-spirobisnitroxide allyl) [138, 141]. Finally, only a relatively small number of n-type radical polymers have been investigated [68, 142-145].

Figure 3a provides an approximate comparison of the theoretical energy densities (compared to Li metal electrode) of several organic radical-polymer battery chemistries relative to a representative Li-ion battery cathode $\left(\mathrm{LiCoO}_{2}\right)$. Notably, poly(PROXYLether), poly(TEMPO-spirobisnitroxide allyl), poly(TEMPO-spirobisnitroxide propargyl) (see numbers 8, 22, and 23 in Figure 3a) have a theoretical capacity above that of $\mathrm{LiCoO}_{2}$ $[99,138,146]$. However, in general radical polymers have slightly lower theoretical capacities and voltages compared to traditional Li-ion batteries.

Figure 3a also illustrates that a theoretical cell potential of ca. $1.4 \mathrm{~V}$ may be achieved by a totally organic radical polymer battery, based on the voltage difference between p-type (positive) poly(TEMPO-norbornene) and n-type (negative) poly(nitronyl nitroxylstyrene) (ID numbers 15 and 2, respectively) [98, 148]. Suga et al. created a totally organic radical-bearing polymer battery using a poly(TEMPO-norbornene) cathode and a poly(galvinoxylstyrene) anode $(0.66 \mathrm{~V}$ cell voltage) [100]. The cell theoretical capacity (per dry weight of both electrodes) was $3.0 \mathrm{Ah} / \mathrm{kg}$ due to a low polymer composition (10 wt \%) (theoretical capacities are $109 \mathrm{Ah} / \mathrm{kg}$ for poly(TEMPO-norbornene) and $42 \mathrm{Ah} / \mathrm{kg}$ for poly(galvinoxylstyrene)). $92 \%$ of the theoretical cell capacity was achieved, and the capacity fade was about $20 \%$ over 250 cycles [100]. This investigation shows the low cell potential and capacity of this all-organic radical polymer battery compared to traditional battery chemistries and motivates further research to close this gap $[146,149,150]$.

\subsection{Radical-bearing conducting polymers}

The third category of radical polymers is radical-bearing conducting polymers, a hybrid of the two previous categories. For example, iodine-doping an acetoxyphenylbearing thiophene conductive polymer improved its conductivity from an insulator 
(b)

(a)
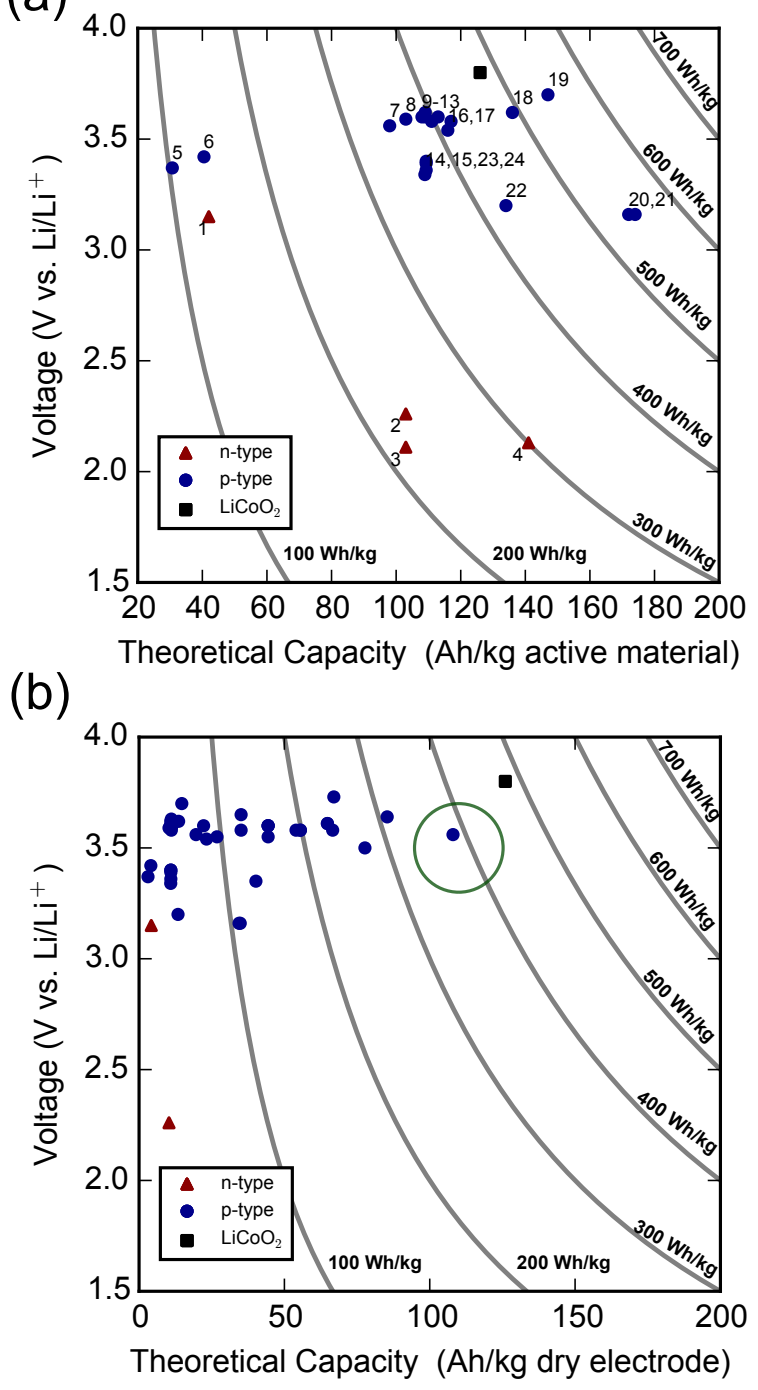

Figure 3: (a) Approximate theoretical specific energy of several organic radical polymers vs. $\mathrm{Li} / \mathrm{Li}^{+}$on basis of active materials. The ID numbers come from Table S2. The $\mathrm{LiCoO}_{2}$ cathode is based on ref. [146]. (b) Results from (a) are converted to theoretical capacity on an electrode mass basis, using dry electrode compositions as reported. The circular region denotes the typical range for these radical polymers on a per-massof-active-material basis. To convert potentials relative to a Li reference electrode, the following conversions were used: $\mathrm{Fc} / \mathrm{Fc}^{+}$is $3.23 \mathrm{~V}$ below $\mathrm{Li} / \mathrm{Li}^{+}$[147] and $\mathrm{Ag} / \mathrm{Ag}^{+}$is $2.87 \mathrm{~V}$ below $\mathrm{Li} / \mathrm{Li}^{+}[92,99,117,148]$. 
$\left(10^{-6} \mathrm{~S} / \mathrm{cm}\right)$ to a semiconductor $\left(10^{-2} \mathrm{~S} / \mathrm{cm}\right)$ [108]. The charge storage mechanism for radical-bearing conducting polymers is similar to that for radical-bearing polymers, except that now both the pendant radical and conducting polymer backbone are redoxactive, albeit at different potentials [151]. Unfortunately, the interplay between the voltage-dependent conductivity of the polymer backbone and redox reactivity of the pendant radical has yet to be independently and systematically investigated [124].

The electroactive nature of both the pendant radical and the polymer backbone complicates the synthesis, polymerization, and storage mechanism. Specifically, unsuccessful efforts have been made to attach radical groups such as $t$-butyl nitroxide, nitroxyl nitroxide, or verdazyl groups directly, to the 3-position of a thiophene ring or to polymerize nitroxide-bearing thiophene monomers [87, 108]. Recent success has been found electropolymerizing TEMPO to poly(thiophene) or PEDOT [28, 151]. Further, di-radical spirobisnitroxide polymers were investigated for their high theoretical capacities $(\sim 174 \mathrm{Ah} / \mathrm{kg})$, but the capacity decreased by $44 \%$ after only 15 cycles when both radical groups were oxidized, likely due to oxidation of the polymer backbone [138]. These examples illustrate the complex behavior of radical-bearing conducting polymers, though only a few systems have been investigated.

The theoretical specific energy of radical-bearing conducting polymers are similar to radical-bearing insulating polymers (see Figure 3a). Significantly, poly(TEMPOthiophene) has a potential of $3.9 \mathrm{~V}$ vs. $\mathrm{Li}^{2} \mathrm{Li}^{+}$, which is comparable to that of $\mathrm{LiCoO}_{2}$, $3.8 \mathrm{~V}$ vs. $\mathrm{Li} / \mathrm{Li}^{+}[87,146]$. Thus, radical-bearing conducting polymers may be effectively used in lithium- and all-organic polymer batteries. A recent all-organic battery was reported with a maximum energy density of $15 \mathrm{Wh} / \mathrm{kg}(1 \mathrm{~V}, 15 \mathrm{Ah} / \mathrm{kg}$ per pPy[ABTS]) made from a viologen-bound polypyrrole anode and ABTS-bound polypyrrole cathode (ABTS is 2,2'-azino-bis(3-ethylbenzothiazoline-6-sulfonic acid)) [152]. While this study highlights the possibility of totally organic batteries, it also shows the present, general challenge of achieving high energy densities.

\subsection{Challenges}

Critical open questions in the field of radical polymers include the stability of radicals and radical polymers, and the prominence of irreversible side reactions. The stability of organic radicals and radical polymers (i.e., minimizing self-discharge and irreversible decomposition) is key for reliable energy storage. Unfortunately, to date, reaction mechanisms and their respective reversibilities (efficiency losses or capacity losses) have yet to be systematically studied and may vary with radical choice, electrolyte composition, cell components, and electrode fabrication procedures. Detailed stability studies of stable radicals and radical polymers (employing experimental, spectroscopic, and computational tools) are imperative to the development and use of these materials in energy storage devices $[17,56]$. Nevertheless, the stability of some radical polymers suggests that these challenges are not insurmountable. Ultimately, the emerging field of radical-based batteries offers a promising, rich, and tunable design space that requires deeper fundamental chemical and mechanistic understanding to propel it forward as a viable energy storage technology. 


\section{Bulk-property electrode design}

To approach the theoretical properties (voltage and capacity) determined by the redox chemistry, electrodes must be designed to promote the kinetic and transport processes that are fundamental to battery performance. In this section, we consider bulk or macroscopic electrode designs, which refer to manufacturing parameters such as composition and thickness. Of course, these design parameters are closely related to microstructural designs that more specifically consider fundamental transport processes (Sec. 4). For example, the conductive carbon composition affects the quality of the electronically conductive network throughout the electrode. Engineering design considerations such as separators, packaging, compression, and choice of electrolyte are also important, but are not discussed here due to the current lack of specific research for radical polymer batteries. A brief and general discussion of some of these considerations can be found in a recent review [17].

While a wide range of bulk design parameters exist, including material selection and electrode preparation methods [153-159], this discussion focuses on composition and thickness, two principle manufacturing parameters, because of their significant impact on cost, performance, and lifetime. Furthermore, low fractions of redox-active material and thin-film electrode designs are the norm for radical polymer batteries because of transport limitations that would arise in thicker electrodes or with a higher polymer (and thus lower conductive carbon) fractions.

\subsection{Composition}

Composition refers to the relative fractions of active material (i.e., radical polymer), conductive carbon, and polymer binder within an electrode. Currently, a large amount of conductive carbon is added to radical polymer electrodes, ranging from 30-80 wt\%, due to the poor electronic conductivity of the polymer [11, 128]. High amounts of carbon also require relatively high amounts of binder, e.g. around $10 \mathrm{wt} \%$ to maintain mechanical integrity. Higher fractions of inactive conductive carbon lower an electrode's gravimetric (and volumetric) charge storage capacity. If the typical carbon and binder content within the electrode were reduced by half, then the storage capacity could potentially be increased by a factor of 5.5. For instance, Suguro et al. increased poly(TEMPO-vinyl ether) composition from 20 to $80 \mathrm{wt} \%$ and showed a slightly decreased achieved capacity, $77 \%$ of theoretical (135 Ah/kg active material) rather than $84 \%$. Nevertheless on a per-electrode-mass basis $(22.8 \mathrm{Ah} / \mathrm{kg}$ and $83.2 \mathrm{Ah} / \mathrm{kg}$, respectively), the electrode with $80 \mathrm{wt} \%$ active material has four-fold higher capacity due to the higher polymer fraction [93].

Figure 3b, intended to be compared to Figure $3 a$, further illustrates how drastically the capacity (and specific energy) decreases because of the low polymer composition of many of the radical polymer electrodes investigated to date. In contrast, the specific energy of $\mathrm{LiCoO}_{2}$ and other traditional Li-ion cathodes do not change significantly because of their high fraction of active material $(>90 \%)$. This effect is even more pronounced on a battery pack scale, where packaging, current collectors, and electrolytes are significant sources of weight. Nakahara et al. made a 180- $\mu \mathrm{m}$-thick poly(TEMPOmethacrylate) (PTMA) electrode (50 wt $\%$ polymer), resulting in an effective $6.2 \mathrm{wt} \%$ active material in the entire battery pack (4 cells in series) [119, 160]. In contrast, for a 
typical Li-ion battery pack this figure would be closer to $35 \mathrm{wt} \%$ active material. Thus, while radical polymers appear theoretically competitive with $\mathrm{Li}$-ion technologies on an active material mass basis, they are currently not competitive on an electrode or pack basis.

\subsubsection{Volumetric composition}

Electronic and ionic conductivities are spatial properties and, thus, depend more on volume fraction than mass fraction [161]. When dry mass fraction is used to represent composition, it does not account for electrode porosity or material density. In many traditional battery chemistries, carbon is the least-dense solid component; however, in radical polymer batteries, it is more dense than the polymer (around $1.9 \mathrm{~g} / \mathrm{cm}^{3}$ for carbon compared to around $1.2 \mathrm{~g} / \mathrm{cm}^{3}$ for polymers). Thus, the volume fraction of carbon is lower than its corresponding mass fraction, and polymer volume fraction is greater than its corresponding mass fraction. Specifically, for a radical polymer electrode having 80 dry wt $\%$ carbon, 10 dry wt $\%$ binder, 10 dry wt $\%$ active polymer and $50 \%$ overall porosity, the electrode volume fraction of carbon and active polymer are around $38 \mathrm{vol} \%$ and $7 \mathrm{vol} \%$, respectively.

\subsubsection{TEMPO-based radical polymers}

As the TEMPO-based polymers have received the most attention, some lessons can be learned from their use $[92,117,162,163]$. Nakahara et al. published the first application of radical polymers for energy storage using poly(TEMPO-methacrylate). They used a low polymer composition (10 wt $\%$ ) and only achieved, or utilized, 70\% of the theoretical capacity $(111 \mathrm{Ah} / \mathrm{kg})$ [162]. Nevertheless, this electrode showed near constant behavior over 500 cycles. Nishide et al. reported similar results [117] Two other studies on poly(TEMPO-methacrylate) investigated high polymer fractions (around $70 \mathrm{wt} \%$ ). Iriyama et al. achieved $65 \%$ of the theoretical capacity; however, after 50 cycles, $40 \%$ of the capacity had been lost [164]. Another study with a similar electrode design achieved $71 \%$ of theoretical capacity, and the capacity only decreased $2 \%$ over 100 cycles at a $1 \mathrm{C}$-rate [165]. The difference in cycling stability of these two high-polymer-fraction electrodes may be due to thickness or differences in the carbon additives used (graphite powder and acetylene black, respectively), but both illustrate pressing challenges facing high polymer composition electrodes, namely transport limitations and capacity fade.

Yoshihara et al. investigated poly(TEMPO-vinyl-ether)/carbon-fiber-based electrodes with various polymer-to-carbon mass ratios, ranging from 80/10 to 20/70 with $10 \mathrm{wt} \%$ binder in each $[94,95]$. They found, as expected, that when carbon fraction is reduced, this decreases electronic conductance and improves specific charge per mass of electrode. This trade-off suggests that an optimal composition exists that maximizes capacity available without substantially hindering accessibility or conductivity.

\subsubsection{Radical-bearing conducting polymers}

Perhaps surprisingly, similar behavior is reported for electrodes made from radicalbearing conducting polymers (see Table S3). In general, the polymer fraction is low $(10 \mathrm{wt} \%)$, the potential ranges from different chemistries range from 0.45 to $1.03 \mathrm{~V}$ vs. $\mathrm{Ag} / \mathrm{Ag}^{+}$, the redox efficiencies (capacity achieved over theoretical capacity) range 
from 20 to $100 \%$, and the capacity decays typically $10 \%$ over 100 cycles $[87,166-$ 169]. In summary, radical-bearing conducting polymers showed promising performance, yet the polymer fractions were consistently low, suggesting that inherent polymer conductivity may be insufficient to enable electrode bulk electronic conductivity without conductive additives.

\subsection{Thickness}

In addition to increased fractions of active material, practical cells require thicker electrodes, with $100 \mu \mathrm{m}$ thickness being a reasonable target number [170]. Thin-film designs limit overall cell capacity because a smaller volume of the cell is devoted to redox-active material for energy storage. The prevalence of thin-film designs is most likely due to inhibited electronic and ionic transport $[95,171]$. However, the failure of prior work to distinguish between ionic and electronic limitations (they exhibit the same effect in many experiments) is a serious impediment to electrode optimization. The following discussion illustrates this issue with case studies of poly(TEMPO-methacrylate) electrodes (see Table S4 for a summary).

Kim et al. specifically investigated the effect of thickness on poly(TEMPO methacrylate) electrodes (40 wt\% polymer) [171]. Two film thicknesses were tested: 17 and 64 $\mu \mathrm{m}$. The Coulombic efficiencies were the same for both electrode thicknesses, based on cyclic voltammetry. The large redox peak separation for the thicker electrode suggests transport restrictions. At a $1 \mathrm{C}$-rate, the thinner film achieved its theoretical capacity while the thicker electrode achieved 50\% of its theoretical capacity. Based on AC impedance, the thicker electrode exhibited larger surface impedance ( $473 \Omega$ compared to $346 \Omega$ for the thin film), which can be attributed to either electrode/electrolyte kinetics or local interfacial transport resistance [171]. While it is difficult to entirely separate transport and kinetics effects using only AC impedance due to the numerous possible equivalent circuits [172], these results suggested local connectivity and reactivity are a bigger problem than bulk conductivity.

Three similar studies with widely different thicknesses $(17,36,180$, and $1000 \mu \mathrm{m})$, provide a rough means to compare the effect of thickness. One study of a poly(TEMPOmethacrylate) composite electrode ( $40 \mathrm{wt} \%$ polymer) shows that doubling the thickness (17 to $36 \mu \mathrm{m}$ ) dropped the achieved capacity from 100 to $60 \%$ of theoretical $(111 \mathrm{Ah} / \mathrm{kg}$ ) [173]. This result was attributed to the insulating nature of the polymer, inhibiting the charge transport. In contrast, Nakahara et al. made a thicker $180 \mu \mathrm{m}$ poly(TEMPOmethacrylate) electrode (50 wt $\%$ polymer), that was able to achieve its theoretical capacity [119]. The difference in achieved capacity suggests that electrode preparation methods may greatly affect performance of thicker electrodes, and these effects require more careful study.

An even thicker electrode (1000 $\mu$ m thick, $50 \mathrm{wt} \%$ polymer) made by Satoh et al. achieved $60 \%$ of its theoretical capacity, and the capacity faded $15 \%$ over 1000 cycles [126]. Notably, the achieved capacity relative to theoretical capacity was the same (60\%) as the Kim et al. study [173], despite the vastly different thicknesses of 36 and 1000 $\mu \mathrm{m}$, respectively. These results suggest another effect, besides thickness, is limiting the electrode performance [173, 174].

In summary, low fraction of redox-active polymer material and thin-film designs are the norm in prior radical polymer work (see Table $\mathrm{S} 4$ for a compilation of conditions 
used). These conditions limit commercial appeal, especially for high energy density rechargeable battery applications. To overcome these challenges, systematic studies of the major sources of resistance in polymer electrodes is essential. Yet, in general, redox efficiency, or the ratio of achieved to theoretical capacity, between $50-100 \%$ are achievable and the cycling behavior is favorable, only declining roughly $10-15 \%$ over $100-1000$ cycles.

\section{Microstructure electrode design}

Bulk material design (e.g., manufacturing parameters and material properties, Sec. 3) gives rise to specific internal or microstructure designs (including material connectivity and dispersion). Each microstructural environment either facilitates or hinders the transport and kinetic processes that underpin battery performance [175, 176]. Further, there is an inherent microstructural trade-off between effective ionic and electronic transport. The pores required for good ionic transport and high reaction surface area interfere with the connectivity of the carbon network required for effective electronic transport [176] (as illustrated in Figure 4a). This section focuses on the electronically and ionically conductive networks and their relationships to electrode microstructure and battery performance.

\subsection{Electronic transport}

Since redox-active materials, including radical polymers, are often electrically insulating or semiconducting, conductive carbon is added to the electrode to facilitate electronic transport. For instance, the electronic conductivity of poly(TEMPO-methacrylate) is $\sim 10^{-6} \mathrm{~S} / \mathrm{cm}$, which is comparable to those of undoped conducting polymers (e.g, $\sim 10^{-6} \mathrm{~S} / \mathrm{cm}$ for poly(3-methylthiophene)) $[105,122,123]$, but much lower than conductive carbon.

Yoshihara et al. performed AC impedance measurements to determine the dominant electronic resistance in a radical polymer electrode (poly(TEMPO vinyl ether)) [94, 95]. They divided the electronic transport into four steps: 1) from redox site to redox site, 2) from radical to carbon fiber, 3) along the carbon fiber, and 4) from the carbon fiber to the current collector $[94,95]$. The greatest resistance was found to be electronic transfer to the current collector (step 4), which was attributed to poor contact (adhesion) between the carbon fibers/polymer and the current collector (illustrating the need of an improved binder, Sec. 5) [95]. Notably, the achieved capacities relative to theoretical in this work were remarkably low ( $\sim 2 \%$, rather than the typical $60-100 \%$ ), yet it provides an excellent model of systematic transport characterization [94].

Recently, Baradwaj et al. showed that TEMPO-based salt acts as a dopant, which improves the electronic conductivity (ionic conductivity was unaffected) of radical polymer electrodes by a factor of 5 [177]. This phenomenon is similar to dopant enhancement in conducting polymers and is due to improved interactions between the salt and the radical pendant. However, at higher dopant loadings (> $10 \mathrm{~mol} \%$ ), the film uniformity degraded, decreasing the conductivity. In addition to determine a means to improve conductivity, dopant studies provide a useful way to probe trade-offs between electronic and ionic transport phenomena within polymer electrodes. 
(a)

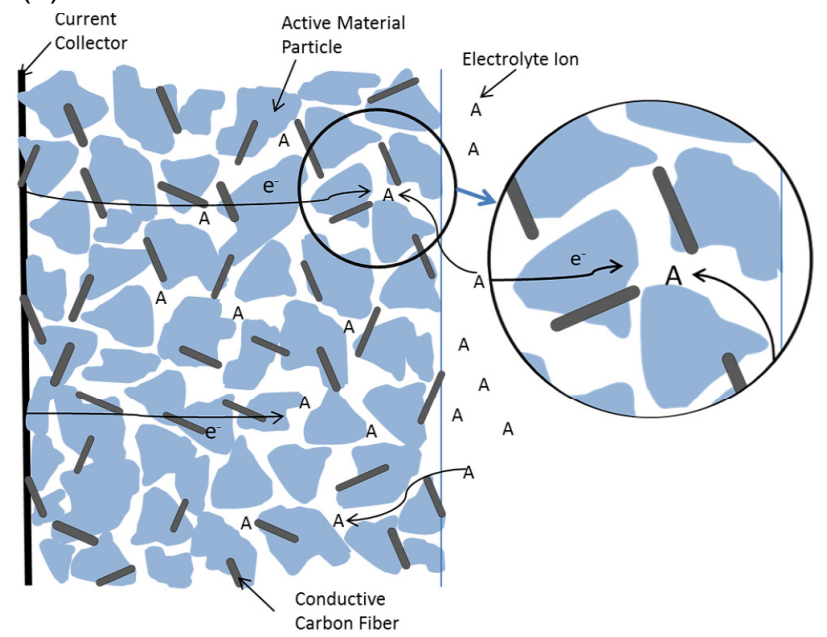

(b)

Diffusing Front

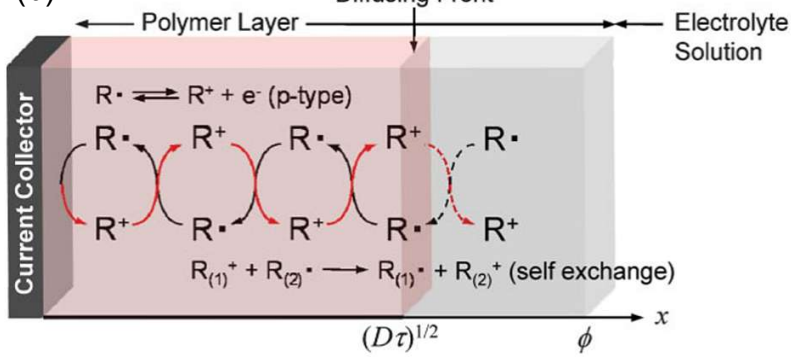

Figure 4: (a) Schematic of a porous battery electrode, illustrating the relationship between microstructure and electronic and ionic transport processes. (b) Positive charge propagation during the oxidation of p-type radical polymers confined at a current collector surface and equilibrated in electrolyte solutions, showing the direction of the charge transport in the slab of the polymer. Reprinted with permission from ref. [170]. Copyright 2009 John Wiley and Sons. 


\subsubsection{Carbon type}

In traditional electrodes for which the carbon fraction is small (e.g. $\sim 5 \mathrm{wt} \%$ ), a fully percolated carbon network, or rather a continuous carbon pathway, does not typically form [176, 178-182]. In an un-percolated carbon network, the carbon serves to connect domains of active material, and thus diminishes the effects of poor electrical surface contact [156, 176, 178, 183, 184].

Different types of carbon (carbon black, graphite, graphene, carbon fibers/filaments, and nanotubes) provide different connectivities and degrees of dispersion, and thus performance $[117,162,185,186]$. Table 1 illustrates the variation of battery performance (capacity, cycling, and cycling stability, or change in capacity) with different carbon types, compositions, C-rates, and thicknesses. The variation is more clearly understood by converting the data to a unifying figure of merit: superficial current density, which is a proxy for power density and is defined as follows:

$$
i=Q w_{\text {active }}(1-\epsilon) \rho_{\text {dry }} t C_{\text {rate }}
$$

where $i$ is the superficial current density, $Q$ is the achieved capacity of active material (units charge/mass active), $w_{\text {active }}$ is the weight fraction of active material in the dry electrode, $\epsilon$ is the electrode porosity, $\rho_{\mathrm{dry}}$ is weighted-average density of the solid components, $t$ is the film thickness, and $C_{\text {rate }}$ is given in units $\mathrm{h}^{-1}$. (The conversion for radical polymer electrodes assumes a porosity of $50 \%$ and material density of 1.9, 1.2, and $1.8 \mathrm{~g} / \mathrm{cm}^{3}$ for carbon black, the radical polymer, and PVdF binder, respectively.)

The superficial current densities in Table 1 range from 0.03 to $0.11 \mathrm{~mA} / \mathrm{cm}^{2}$ for these radical polymers, at least one order of magnitude lower than that for a $\mathrm{LiCoO}_{2}$ cathode $\left(1.3 \mathrm{~mA} / \mathrm{cm}^{2}\right)$ [171, 173, 174, 187]. This Li-ion comparison cathode was assumed to have the following properties: $2.2 \mathrm{~g} / \mathrm{cm}^{3}$ dry apparent density, $35 \%$ porosity, $75 \mu \mathrm{m}$ thick, $90 \mathrm{wt} \%$ active material, $130 \mathrm{Ah} / \mathrm{kg}$ capacity, and $1 \mathrm{C}$-rate. Thickness has the most direct effect on the superficial current density. Notably, for these radical polymer electrodes to have a similar current density to $\mathrm{LiCoO}_{2}$ electrodes, a radical polymer electrode must be $200 \mu \mathrm{m}$ thick and have active polymer composition of 78 $\mathrm{wt} \%$, reinforcing the need for higher polymer composition and thicker (or possibly less porous) radical polymer electrodes in order to compete with traditional Li-ion batteries (see Sec. 3).

Table 1: Summary of poly(TEMPO-methacrylate) positive electrodes with various conductive carbon additives. NR means not reported. The composition is the weight percentages of polymer/carbon/binder, respectively. Redox Eff. means the redox efficiency, or the ratio of achieved to theoretical capacity. $i$ means the calculated superficial current density. Stability refers to change in capacity due to cycling.

\begin{tabular}{|c|c|c|c|c|c|c|c|c|c|c|c|}
\hline \multicolumn{4}{|c|}{$\begin{array}{l}\text { Electrode } \\
\text { properties }\end{array}$} & $\begin{array}{c}\text { Poten } \\
\text {-tial }\end{array}$ & \multicolumn{3}{|c|}{$\begin{array}{c}\text { Initial } \\
\text { performance }\end{array}$} & \multicolumn{3}{|c|}{$\begin{array}{c}\text { Cycling } \\
\text { performance }\end{array}$} & \multirow[b]{2}{*}{ Ref. } \\
\hline Carbon & $\begin{array}{l}\text { Compo- } \\
\text { sition w/w/w } \\
(w t \%)\end{array}$ & Binder & $\begin{array}{l}\text { Thick- } \\
\text { ness } \\
(\mu \mathbf{m})\end{array}$ & \begin{tabular}{c|}
$(\mathbf{V}$ \\
vs. $\left.\mathbf{L i} / \mathbf{L i}^{+}\right)$
\end{tabular} & $\begin{array}{c}\text { Redox } \\
\text { Eff. } \\
(\%)\end{array}$ & C-rate & $\begin{array}{c}i(\mathbf{m A} / \\
\left.\mathbf{c m}^{2}\right)\end{array}$ & Cycles & C-rate & $\begin{array}{c}\text { Stabil- } \\
\text { ity } \\
(\%)\end{array}$ & \\
\hline $\begin{array}{l}\text { carbon } \\
\text { black }\end{array}$ & $50 / 40 / 10$ & $\mathrm{FPO}^{a}$ & 1000 & $3.58^{b}$ & $60.4^{c}$ & 0.7 & & 1000 & 0.03 & -15 & [126] \\
\hline $\begin{array}{l}\text { ketjen } \\
\text { black }\end{array}$ & $60 / 30 / 10$ & $\operatorname{LiPA}^{d}$ & NR & $3.61^{e}$ & 95.4 & 1 & & 1000 & 20 & -4 & [147] \\
\hline $\begin{array}{l}\text { ketjan } \\
\text { black }\end{array}$ & $60 / 30 / 10$ & PVdF & NR & $3.61^{e}$ & NR & NR & & NR & NR & NR & [147] \\
\hline
\end{tabular}




\begin{tabular}{|c|c|c|c|c|c|c|c|c|c|c|c|}
\hline \multicolumn{4}{|c|}{$\begin{array}{l}\text { Electrode } \\
\text { properties }\end{array}$} & $\begin{array}{c}\text { Poten } \\
\text {-tial }\end{array}$ & \multicolumn{3}{|c|}{$\begin{array}{c}\text { Initial } \\
\text { performance }\end{array}$} & \multicolumn{3}{|c|}{$\begin{array}{c}\text { Cycling } \\
\text { performance }\end{array}$} & \multirow[b]{2}{*}{ Ref. } \\
\hline Carbon & $\begin{array}{c}\text { Compo- } \\
\text { sition w/w/w } \\
(w t \%)\end{array}$ & Binder & $\begin{array}{l}\text { Thick- } \\
\text { ness } \\
(\mu \mathbf{m})\end{array}$ & $\begin{array}{c}\mathbf{V} \\
\text { vs. } \mathbf{L i} / \mathbf{L i} \mathbf{i}^{+}\end{array}$ & $\begin{array}{l}\text { Redox } \\
\text { Eff. } \\
(\%)\end{array}$ & C-rate & $\begin{array}{c}i(\mathbf{m A} / \\
\left.\mathbf{c m}^{2}\right)\end{array}$ & Cycles & C-rate & $\begin{array}{l}\text { Stabil- } \\
\text { ity } \\
(\%)\end{array}$ & \\
\hline $\begin{array}{c}\text { acetylene } \\
\text { black }\end{array}$ & $77 / 15 / 8$ & $\mathrm{PVdF}$ & NR & $3.64^{e}$ & 70.6 & 0.2 & & 100 & 1 & -2 & [165] \\
\hline Super P & $20 / 70 / 10$ & PVdF & 17 & $3.6^{e}$ & 100 & 1 & 0.03 & 200 & 1 & -16 & [187] \\
\hline Super P & $40 / 50 / 10$ & PVdF & 17 & $3.6^{e}$ & 100 & 1 & 0.06 & 100 & 1 & -8 & [173] \\
\hline Super $P$ & $40 / 50 / 10$ & $\mathrm{PVdF}$ & 36 & $3.6^{e}$ & 61.3 & 1 & 0.08 & 100 & 1 & NR & [173] \\
\hline Super P & $40 / 50 / 10$ & $\mathrm{PVdF}$ & 17 & $3.55^{e}$ & 100 & $1-10$ & 0.06 & 400 & 1 & -4 & [174] \\
\hline Super $\mathrm{P}$ & $40 / 50 / 10$ & PVdF & 17 & $3.6^{e}$ & 100 & 1 & 0.06 & 100 & 1 & -10 & [171] \\
\hline Super $P$ & $40 / 50 / 10$ & $\mathrm{PVdF}$ & 64 & $3.6^{e}$ & 49.5 & 1 & 0.11 & 100 & 1 & -30 & [171] \\
\hline Super P & $40 / 50 / 10$ & $\mathrm{PVdF}$ & 17 & $3.6^{e}$ & 100 & 1 & 0.06 & 200 & 1 & -12 & [187] \\
\hline Super P & $60 / 30 / 10$ & PVdF & 17 & $3.58^{e}$ & 71.2 & 1 & 0.06 & 200 & 1 & -11 & [187] \\
\hline graphite & $10 / 80 / 10$ & PTFE & $150-250$ & $3.58^{f}$ & 69.4 & 0.4 & & 500 & 12 & -5 & [162] \\
\hline graphite & $70 / 26 / 4$ & $\begin{array}{l}\text { poly- } \\
\text { mer }\end{array}$ & NR & $3.5^{f}$ & 64.9 & NR & & 50 & NR & -35 & [164] \\
\hline $\begin{array}{c}\text { graphene/ } \\
\mathrm{CB}^{g}\end{array}$ & $10 / 80 / 10$ & $\mathrm{PVdF}$ & NR & $2.8,3.8^{h, i}$ & 100 & 1 & & 20000 & 100 & -55 & [188] \\
\hline VGCF & $10 / 80 / 10$ & PVdF & & $3.58^{j}$ & 69.4 & 1.2 & & 1000 & NR & 0 & [117] \\
\hline VGCF & $30 / 60 / 10$ & $\mathrm{PVdF}$ & 50 & $3.6^{f}$ & $99.1^{c}$ & 1 & & 1000 & 1 & -11 & [119] \\
\hline $\mathrm{VGCF}^{f}$ & $50 / 45 / 5$ & $\begin{array}{l}\mathrm{CMC} / \\
\mathrm{PTFE}^{k}\end{array}$ & 180 & NR & NR & NR & & 100 & 0.7 & -18 & [189] \\
\hline VGCF & $50 / 45 / 5$ & $\begin{array}{c}1 / 4 \\
\mathrm{CMC}^{2} \\
\mathrm{PVdF}^{l}\end{array}$ & $130-180$ & $3.58^{f}$ & 99.1 & 1 & & 25 & 5 & -13 & [160] \\
\hline SWNT & $96 / 4 / 0$ & N/A & NR & $0.8^{m, n}$ & 91 & 9 & & NR & NR & NR & [190] \\
\hline & NR & NR & NR & $0.76^{n, o}$ & 99.1 & $1-50$ & & 1000 & NR & 0 & [63] \\
\hline & NR & NR & NR & $0.37^{p, q}$ & NR & NR & & NR & NR & NR & [133] \\
\hline
\end{tabular}

${ }^{a}$ FPO is fluorinated polyolefin. ${ }^{b} 1 \mathrm{M} \mathrm{LiPF}_{6}$ ethylene carbonate/diethyl carbonate. ${ }^{c}$ Assumed a theoretical capacity of $111 \mathrm{Ah} / \mathrm{kg}$ because it was not reported. ${ }^{d} \mathrm{LiPA}$ is lithium polyacrylate. ${ }^{e} 1 \mathrm{M} \mathrm{LiPF}_{6} 1 / 1$ vol ethylene carbonate/dimethyl carbonate. ${ }^{f} 1 \mathrm{M} \mathrm{LiPF}_{6} 3 / 7$ vol ethylene carbonate/diethyl carbonate. ${ }^{g}$ $60 / 20 \mathrm{wt} \%$ graphene and carbon black (CB). ${ }^{h}$ Reduced from p-type to radical and radical to n-type. ${ }^{i}$ electrolyte not reported. ${ }^{j} 0.1 \mathrm{M}$ tetrabutylammonium tetrafluoroborate acetonitrile. ${ }^{k} \mathrm{CMC} / \mathrm{PTFE} 4 / 1 \mathrm{wt} \%$. ${ }^{l} \mathrm{CMC} / \mathrm{PVdF} 4 / 1 \mathrm{wt} \% .{ }^{m} 0.1 \mathrm{M}$ tetrabutylammonium perchlorate acetonitrile. ${ }^{n} \mathrm{vs} . \mathrm{Ag} / \mathrm{Ag}^{+} .{ }^{o} \mathrm{LiPF}_{6}$ ethylene carbonate/diethyl carbonate. ${ }^{p} 0.1 \mathrm{M}$ tetrabutylammonium hexafluorophosphate acetonitrile. ${ }^{q}$ vs. $\mathrm{Fc} / \mathrm{Fc}^{+}$.

In terms of microstructure impact, Kim et al. showed that higher polymer fractions (60 wt \%) electrode with carbon black additive led to the polymer particles fusing into layers, impeding conductivity and decreasing the achieved capacity to $71 \%$ of the theoretical capacity $(111 \mathrm{Ah} / \mathrm{kg}$ ). In contrast, low polymer fractions (20 and 40 wt $\%$ ) electrodes had well-defined particle morphologies, and achieved their theoretical capacity $[174,187]$. Additionally, Guo et al. sought to take advantage of the 3D structure of graphene in a $80 \mathrm{wt} \%$-carbon poly(TEMPO-methacrylate) composite electrode (60 wt $\%$ graphene reduced from graphene oxide and $20 \mathrm{wt} \%$ carbon black). After 100 cycles at $1 \mathrm{C}$-rate, the non-graphene-containing electrode's capacity faded 3 times more $(76 \mathrm{Ah} / \mathrm{kg})$ than graphene-containing electrode $(169 \mathrm{Ah} / \mathrm{kg})$. Even at $100 \mathrm{C}-$ rate, the graphene-containing electrode maintained a capacity above $100 \mathrm{Ah} / \mathrm{kg}$ over 20,000 cycles, indicating an efficient conductive network [188]. However in terms of specific energy, this performance is not ideal because of the constantly declining voltage during discharge, likely due to the multiple redox steps. Nonetheless taken together, these 
studies illustrate the impact of carbon structure on battery performance [186] (see Table 1).

\subsubsection{Chemical design using conducting polymers}

Rather than mixing in conductive additive, conductive pathways may be built into the polymer via chemical design: electropolymerization and copolymerization of conducting polymers $[112,191]$. Electropolymerization and electrochemical deposition of conducting polymers can provide improved electronic connections within the electrode with the possibility of self-limiting polymerization (i.e., a coating that is naturally formed at the optimal thickness) [27, 118, 168, 191, 192].

While conducting polymers have been used as conductive additives for $\mathrm{LiFePO}_{4}$ electrodes $[27,115,116]$, polymer-based electrodes allow additional designs via copolymerization of radical polymers and conducting polymers [193]. Several recent studies show the effectiveness of this method [11, 28, 151, 191, 194, 195]. Specifically, Oyaizu et al. co-polymerized poly(aniline) and poly(TEMPO-norbornene), and the electrode provides a flat discharge curve even at high discharge rates (10-40 C-rate) [191]. Recently, Casado et al. electropolymerized TEMPO-bearing PEDOT, which gave electronic conductivity of $5.7 \times 10^{-2} \mathrm{~S} / \mathrm{cm}$, which is lower than pure PEDOT, but higher than nonconducting radical polymers $\left(10^{-5} \mathrm{~S} / \mathrm{cm}\right)$ [28]. Further, they showed that radical conducting polymer could replace for carbon additives and polymeric binder in Li-ion batteries, and improve the electrode rate capabilities (see Figure 5). In general, mixing conducting and radical polymers in the same electrode is a relative unexplored, but promising approach with innumerable chemical combinations to potentially optimize electronic transport and increase electrode energy density (by reducing additives).

Finally, molecular dynamics simulations may be used to understand the mechanism of charge transport in conducting polymers, and its relationship to different chain configurations and polymer structures [104, 196, 197]. Using molecular dynamics, Kemper et al. elegantly related radical-polymer molecular structure to electronic structure (poly(TEMPO methacrylate) [198]. They showed that 85\% of charge transfer occurs between different polymer chains (effective diffusion length, $5.5 \AA$ ). Similar modeling efforts could be used to investigate the electronic conductivity within radical-bearing polymers, block copolymers, and composite electrodes to guide electrode design. Overall modeling for radical polymer batteries, particularly toward improved electronic conductivity, is a relatively open field.

\subsection{Ionic transport}

Ionic transport includes diffusion and migration of ions in the electrolyte through the electrode during charge and discharge. Ionic transport is facilitated most commonly by a network of liquid-filled pores and less commonly by solid polymer electrolytes. Ionic conductivity may be measured independently of the electronic conductivity for porous electrodes by using restricted-diffusion or polarization-interrupt experiments [199, 200]. Even though ionic conductivity is the most commonly measured and reported electrolyte property in the battery community, it does not completely describe all ion transport processes. For a binary electrolyte (one cation, one anion, and one solvent), the electrolyte diffusivity and ion transference number are also needed for a 

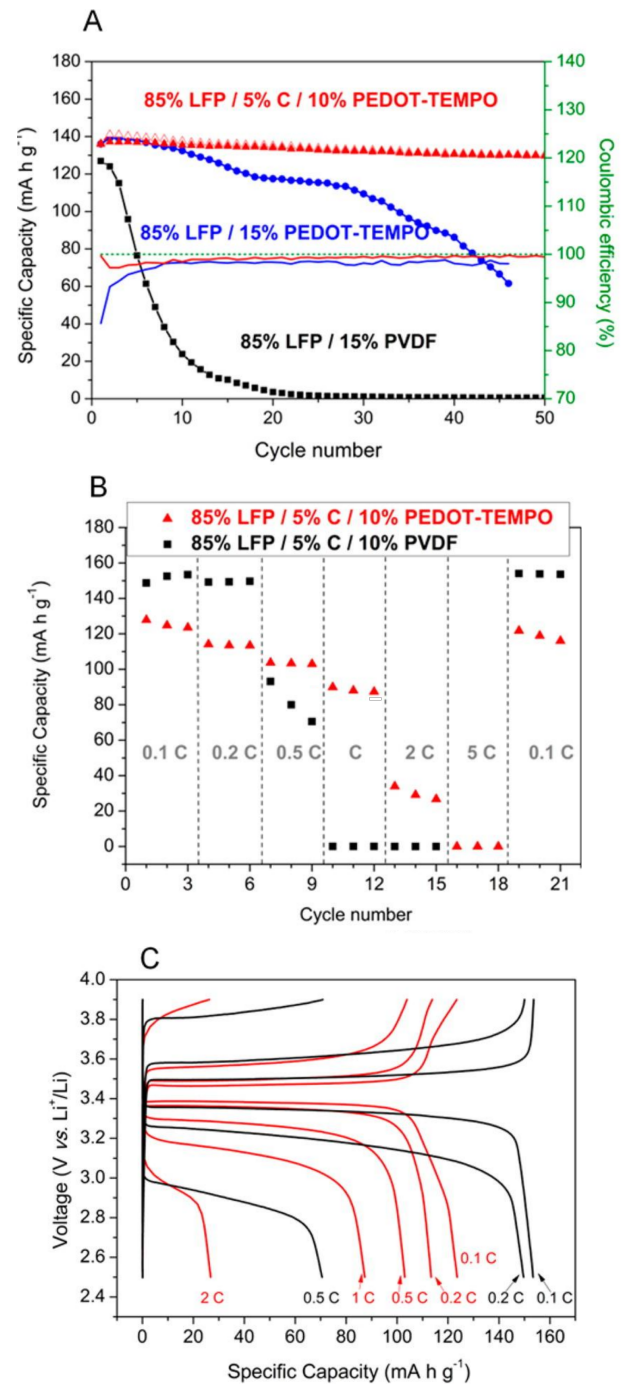

Figure 5: Cell performance of $\mathrm{LiFePO}_{4}$ (LFP) cathodes. (A) Discharge capacity and Coulombic efficiency at 0.1 $\mathrm{C}$ with (blue circle) 15\% PEDOT-TEMPO, (red triangle) $10 \%$ PEDOT-TEMPO and 5\% carbon, and (black square) $15 \%$ PVDF. (B) C-rate capability and (C) voltage profile at different $\mathrm{C}$ rates for (red line) 10\% PEDOT-TEMPO and 5\% carbon and (black line) 10\% PVDF and 5\% carbon. Reproduced from ref. [28] (ACS AuthorChoice). 
full transport description. The effective ionic conductivity and diffusivity can be used as a proxy for comparing the relative merits of different electrodes and materials, or these properties may be related to tortuosity that indicates the relative amount of ionic obstruction within an electrode [199, 201, 202].

\subsubsection{Pore-structure effects}

Relatively few studies have investigated the effect of changing the porosity of radical polymer electrodes. This is most likely due to their typical thin-film design (10$100 \mu \mathrm{m}$ thick). Suga et al. suggested that beyond a polymer film thickness of $0.26 \mu \mathrm{m}$ the redox behavior becomes electrolyte diffusion-controlled for cross-linked poly(TEMPOnorbornene) coated onto indium tin oxide (ITO) [96]. When bulk transport is a limiting factor, one will observe diminished material utilization with increasing film thickness, presenting a fundamental challenge to designing thicker electrodes [203].

Furthermore cycling alters the polymer structure, Kim et al. showed for a poly(TEMPOmethacrylate) electrode made of 100-nm-diameter polymer particles that ionic transport was facilitated during the first 100 cycles likely due to swelling and the small particle size. However, by 400 cycles the polymer particles had fused into larger particles, creating an insulated layer that hindered electronic and ionic transport (similar to high polymer composition electrodes, see Sec. 3.1) [164, 171, 174].

Improved pore design can be co-optimized to enable efficient electronically and ionically conductive networks. Previous work in unrelated fields has shown that it is possible to tailor and functionalize porous carbon architectures [192, 204], to prepare porous polymers, including polymer gel electrolytes [205, 206], and to create threedimensional electrode structures and pore architectures [192, 201, 202, 204, 207, 208]. This knowledge can be leveraged to improve the design of porous radical polymer electrodes by preparing porous polymers or attaching radical polymers to a porous carbon support. Both these approaches provide numerous design possibilities that can create more effective conductive networks in radical polymer electrodes, and improve energy density.

\subsubsection{Polymer effects}

Suguro et al. investigated the impact on ionic conductivity of block copolymers of poly(TEMPO-vinyl ether) with various chain lengths of ethylene oxide [209]. Ethylene oxide has been showed to have a high Li-ion conductivity. Poly(TEMPO-vinyl ether)/tri(ethylene oxide) has an ion conductivity of $5.2 \mathrm{mS} / \mathrm{cm}$ compared to $4.2 \mathrm{mS} / \mathrm{cm}$ for poly(TEMPO-vinyl ether). The poly(TEMPO-vinyl ether) and poly(TEMPO-vinyl ether)/ethylene oxide copolymers achieved $76 \%$ of the theoretical capacity $(135 \mathrm{Ah} / \mathrm{kg})$ while triethylene-oxide-based copolymer achieved $84 \%$ of the theoretical capacity [209]. The authors attribute the increased achieved capacity for the poly(TEMPO-vinyl ether)/tri(ethylene oxide) copolymer to the improved ionic conductivity. Hence, copolymerization could enhance both ionic and electronic conductivity for radical polymers (via copolymerizing with conducting polymers).

In some cases, diffusion coefficients in thin-film radical-bearing polymer electrodes appear quite respectable, while in other cases they do not. Poly(TEMPO-methacrylate) is reported to have an apparent diffusion coefficient similar to poly(vinylferrocene), namely $10^{-8} \mathrm{~cm}^{2} / \mathrm{s}[63]$. This result was obtained with cyclic voltammetry, which 
averages the diffusivities of redox reactants and products. A process intrinsic to ion transport in radical polymer electrodes is the incorporation and release of "chargecompensating" ions. Oyaizu et al. determined diffusion coefficients of the perchlorate ions ( $0.1 \mathrm{M}$ tetrabutylammonium perchlorate in acetonitrile) to be on the order of $10^{-10}$ $\mathrm{cm}^{2} / \mathrm{s}$ in poly(TEMPO-norbornene) and poly(PROXYL-ether) electrodes [99, 129]. Other chemistries suggest similar diffusion values for perchlorate ions [100, 148].

\subsubsection{Liquid-electrolyte effects}

The majority of reported radical polymer batteries use lithium as the anode, and as such require fluorinated lithium salts $\left(e . g ., \mathrm{LiPF}_{6}\right)$ as the active electrolyte ions and organic carbonates as the solvent. In fact only a few studies use non-lithium-based electrolytes [210, 211]. One such study by Dai et al. used a sodium-based electrolyte $\left(\mathrm{NaClO}_{4}\right)$ [210]. The $30 \mathrm{wt} \%$ poly(TEMPO-norbornene) polymer battery with a sodium metal anode had an average discharge potential of $3.44 \mathrm{~V}$ vs. $\mathrm{Na}^{+} / \mathrm{Na}$. The initial charging capacity was $296 \mathrm{Ah} / \mathrm{kg}$ while the initial discharge capacity was $75 \mathrm{Ah} / \mathrm{kg}$, which is $69 \%$ of theoretical capacity [210]. The discrepancy between the initial charge and discharge capacities suggests electrolyte decomposition, a passive surface layer (i.e., solid-electrolyte interphase), or possibly sodium dendrite formation. The capacity decreased by $36 \%$ in 50 cycles at a C-rate around 1 to 2 [210]. Significant work is needed to expand radical polymers beyond lithium-based systems, and, indeed, many of the analytical tools and direct measurement methods used to study ionic transport in other battery systems can be applied to radical polymers [199, 212].

A limited range of electrolytes have been tested and new electrolytes such as ionic liquids (ILs) have not been deeply investigated, despite the promise of improved ionic conductivity [211]. Lee et al. proposed IL-tethered organic radicals, with one and two TEMPO units as viscous stationary liquids for positive electrode applications in rechargeable Li batteries [213]. The mono- and di-radicals had theoretical capacities of 59 and $80 \mathrm{Ah} / \mathrm{kg}$, respectively, formed homogeneous coating on conductive carbon, exhibited no morphological changes after 100 charge-discharge cycles, and observed some capacity fade at higher C-rates. Similar suppression of agglomeration was reported by cycling an electrode based on poly(TEMPO-methacrylate) in ionic liquid electrolytes [214]. Unfortunately these IL-supported radicals exhibit low capacities (lower than polymerized TEMPO, see Sec. 2) which hamper their applicability, but the authors note that this approach has broad utility as a design tool.

\subsection{Kinetics}

Battery performance also depends on the speed of the redox reactions, i.e. kinetics. The kinetics can be described using the heterogeneous electron-transfer rate constant and the self-exchange rate constant. The heterogeneous rate constant describes the redox reactions at the electrochemical interface while the self-exchange rate constant describes electron transfer between adjacent redox centers. The self-exchange kinetics also relate to the electronic conductivity of the polymer (see Figure $4 \mathrm{~b}$ ). The heterogeneous rate constant may be measured using cyclic voltammetry, chronoamperometry, or AC techniques [129, 215-217] while self-exchange rate constants are calculated according to Marcus theory or from electron spin resonance measurements [218, 219]. 
Radical polymers generally exhibit rapid heterogeneous and self-exchange rate constants. The heterogeneous rate constants (or the redox reaction rates) of TEMPO and poly(4-nitronylnitroxylstyrene) are around an order of magnitude faster $\left(10^{-1}\right.$ $\mathrm{cm} / \mathrm{s})$ than those for metal complexes $\left(10^{-3}-10^{-2} \mathrm{~cm} / \mathrm{s}\right)[220,221]$ and many orders of magnitude faster than for disulfides $\left(10^{-8} \mathrm{~cm} / \mathrm{s}\right)[63,126,148,218]$. Additionally, the electron self-exchange rate constant for TEMPO [129], poly(PROXYL-ethylene oxide) [129], and poly(TEMPO-norbornene) cross-linked by coumarin [152] are approx. $10^{8}$, $10^{7}$, and $10^{5}(\mathrm{M} \mathrm{s})^{-1}$, respectively. In comparison, the exchange rate constants of poly(vinylferrocene) and viologen-containing polymers are $10^{5}(\mathrm{M} \mathrm{s})^{-1}[129,152]$. The rapid kinetics of the TEMPO-based radicals have been attributed to minimal structural changes during the redox reactions and small distances between radicals on polymer backbone $[99,170]$.

Notably, the self-exchange rate constant relates to electronic conductivity along the polymer backbone [219]. In this light, the rapid self-exchange kinetics suggest the potential for good electronic conductivity for the radical polymer. Nevertheless, to date, radical polymer electrodes require a large fraction of conductive carbon to effectively operate, suggesting poor electronic conductivity. Per Jernigan et al., a rate constant of $10^{5}\left(\mathrm{M} \mathrm{s}^{-1}\right.$ corresponds to an electronic conductivity of $10^{-3} \mathrm{mS} / \mathrm{cm}$ [219]. For the radical polymers, poly(PROXYL-ethylene oxide) and poly(TEMPOnorbornene)/coumarin, the kinetics would correspond to an approximate electronic conductivity of $10^{-3}-10^{-1} \mathrm{mS} / \mathrm{cm}$, which is consistent with the conductivity measurements by Rostro et al. for poly(TEMPO-methacrylate) [122, 129, 152]. Notably, these polymer electronic conductivities are at least three orders-of-magnitude below the bulk values for $\mathrm{LiCoO}_{2}$ composite electrodes, which are reported as $\sim 200 \mathrm{mS} / \mathrm{cm}$ [149]. Thus although the kinetics are rapid, they are not so fast as to translate into electronic conductivity comparable to traditional inorganic-based low-carbon-fraction electrodes.

\section{Binding methods}

To maintain effective conductive networks (electronic and ionic) during cycling, binding methods are essential. Binding methods physically hold the electrode together and maintain the microstructure that is crucial to battery performance. A few factors that contribute to capacity fade include: 1) increased resistance due to oxidation, 2) selfdischarge or loss of active material (e.g., dissolution), and 3) loss of cyclable electrolyte salts (e.g., Li ions) due to irreversible side reactions [222].

Self-discharge is a major concern for radical polymer batteries. For instance, one study reported that a poly(TEMPO-methacrylate) cathode self-discharged $38 \%$ of its capacity in one week, but recovered more than $98 \%$ of this capacity in the next cycle [160]. Several authors attribute such self-discharge to the dissolution of the polymer into the electrolyte solution where it acts as a redox shuttle [160, 223]. Hence, effective binding methods are needed to secure the polymer within the electrode to enable effective charge storage.

\subsection{Polymer binders}

The most common binding method is a fluorinated polymer binder such as poly(vinylidene fluoride) (PVdF) or poly(tetrafluoroethylene) (PTFE) [174, 209]. These are expected to 
be reasonably durable, and have been widely used in comparable electrochemical environments. Komaba et al. compared poly(TEMPO-methacrylate) composite electrodes with two different polymer binders: lithium polyacrylate and PVdF [147]. An electrode with $60 \mathrm{wt} \%$ active polymer and $10 \mathrm{wt} \%$ lithium polyacrylate achieved $95 \%$ of its theoretical capacity, the capacity decreased only $4 \%$ over 1000 cycles. This electrode had a lower resistance than similar PVdF-based electrodes (e.g., PVdF-based electrode has $71 \%$ of its theoretical capacity and capacity decreased $11 \%$ over 200 cycles [187]). The authors attributed these differences to the swelling and partial gelling of polyacrylate, creating more surface area in contact with the electrolyte and thus improving electrode cohesion and minimizing capacity fade. Notably, Casado et al. recently showed that poly(TEMPO-EDOT) radical conducting polymer could be used as replacement for carbon additives and polymeric binder in Li-ion batteries [28].

\subsection{Molecular weight of the radical polymer}

Increasing the molecular weight of the active radical polymer is another method to prevent radical polymer dissolution and capacity fade. A 180-nm-thick poly(PROXYLethylene oxide) composite electrode with $10 \mathrm{wt} \%$ radical polymer $(10 \mathrm{wt} \% \mathrm{PVdF}$ binder) nearly achieved its theoretical capacity, 99\% [99], and had a capacity fade of $15 \%$ over 1000 cycles. The authors, Oyaizu et al., attributed the lack of self-discharge by dissolution to the high molecular weight $\left(10^{5} \mathrm{~g} / \mathrm{mol}\right)$. Another study explicitly investigated two similar polymers (poly(TEMPO-oxanorbornene) derivatives) with different polymer weights: 80,000 and $112,000 \mathrm{~g} / \mathrm{mol}$ [97]. These two 10 -wt\%-polymer electrodes achieved $98 \%$ and $85 \%$ of their theoretical capacity, respectively; though the cycling data alone is inconclusive because for the heavier polymer the capacity increased with cycling, which is attributed to increased contact between the electrode and electrolyte due to swelling.

\subsection{Cross-linking}

Cross-linking polymer chains decreases solubility and, thus, capacity fade. Bugnon et al. reported that the capacity for poly(TEMPO-methacrylate), which is soluble in organic solvents (e.g., THF and ethyl carbonate), faded $74 \%$ in 25 cycles at $0.1 \mathrm{C}-$ rate. They showed that cross-linking rendered the polymer insoluble, with only slight swelling, and enabled near constant capacity (6\% fade) over 200 cycles at a 2 C-rate. Similar cross-linking effects on battery performance have been investigated for several polymer chemistries: TEMPO-bearing methacrylate, norbornene, and acetoacetate polymers [96, 100, 129, 223, 224] (see Table S5). Various other studies leveraged, but did not analyze the effect of polymer cross-linking on polymer solubility and capacity fade [100, 138, 147, 225, 226].

An additional benefit of cross-linking may be enhanced ionic transport via a more rigid, swollen pore structure. Diffusion coefficients describe the electrolyte ion mobility, and may be used as proxy for ionic transport (see Sec. 4.2). Ibe et al. reported the diffusion coefficients for poly(TEMPO-acetoacetate-TMPTA) and poly(TEMPOacetoacetate-PETA) as $5.2 \times 10^{-9}$ and $2.6 \times 10^{-9} \mathrm{~cm}^{2} / \mathrm{s}$, respectively. Both values are similar to that of poly(vinylferrocene) of $10^{-8} \mathrm{~cm}^{2} / \mathrm{s}[63,224]$. Notably, the $40 \%$ lower cross-link density of the TMPTA-based polymer doubles the diffusion coefficient, 
suggesting that there may be an optimal cross-linked density to balance the trade-off between preventing dissolution and promoting ionic transport. Further research is necessary to more precisely understand the relationship between cross-link density and battery performance.

\subsection{Surface attachment (brushes)}

Surface attachment has been investigated as a non-cross-linking binding method [227-230]. Lin et al. used silica nanoparticles to create a non-cross-linking, polymerbinder-free method to overcome capacity fade caused by polymer dissolution [227]. They created poly(TEMPO-methacrylate) brushes attached to silica nanoparticles, which were then formed into a $20 \mu \mathrm{m}$ thick electrode with $25 \mathrm{wt} \%$ polymer. Unfortunately, the electrode fraction occupied by silica is not reported. Larger nanoparticles $(15,40$, and $400 \mathrm{~nm})$ resulted in higher achieved capacities $(75 \%, 85 \%$, and $100 \%$ of theoretical capacity, respectively). The capacity fade for the $40 \mathrm{~nm}$ nanoparticle electrode was $4 \%$ over 300 cycles compared to $18 \%$ for a typical poly(TEMPO-methacrylate) electrode, indicating the efficacy of the surface attachment method [227].

In another surface attachment study, Wang et al. bound poly(TEMPO-methacrylate) to a silane-coated ITO current collector [231]. Comparing this chemically-attached polymer electrode to one that is spin-coated, the authors show that after 50 cycles, the capacity of the spin-coated cathode decayed to nearly zero whereas the chemicallybound brush based cathode only deteriorated 5\% [231]. Thus, ITO/silane-bound poly(TEMPO-methacrylate) cathodes appear to be an effective means to improve cycle life by minimizing polymer dissolution.

Surface attachment methods may enable the effective use of thicker electrodes. Hung et al. showed that for brushes longer than $55 \mathrm{~nm}$, that were attached to a silica/ITO surface, the bases of the brushes were not oxidized (reacted) over 10 minute oxidation time [232]. If the oxidation time is increased, it caused over-oxidation of the brush tops, which decreased the capacity. The authors clearly showed the trade-off between increased brush length and capacity, and increased resistance (highlighted in Sec. 3). This is similar to trade-off between electrode thickness (resistance) and capacity.

\subsection{Three-dimensional ordered lattices}

Ordered lattices or porous architectures, including covalent organic frameworks, enable polymer surface attachment and can create improved electronic and ionic conductive networks and battery performance at higher discharge rates [192, 208, 233-235]. Kim et al. created an ordered nanocomposite by attaching poly(TEMPO-methacrylate) to a mesocellular carbon foam. This electrode nearly achieved its theoretical capacity, and had minimal capacity fade over 50 cycles at $1 \mathrm{C}$-rate [233]. Notably at a $50 \mathrm{C}$-rate, the capacity faded $25 \%$ while that of a traditional poly(TEMPO-methacrylate) electrode declined $80 \%$. Despite the improved electronic network formed by the carbon foam, carbon black was still added to the nanocomposite to achieve the desired performance.

Furthermore, Lin et al. synthesized a three-dimensionally-ordered macroporous (3DOM) poly(TEMPO-methacrylate)-brush electrode (see Figure 6) [236]. The brush was chemically attached to the lattice surface, which was made of poly(pyrrole); no additional conductive carbon was used. They compared a planar electrode to the 3.5- $\mu \mathrm{m}$ 

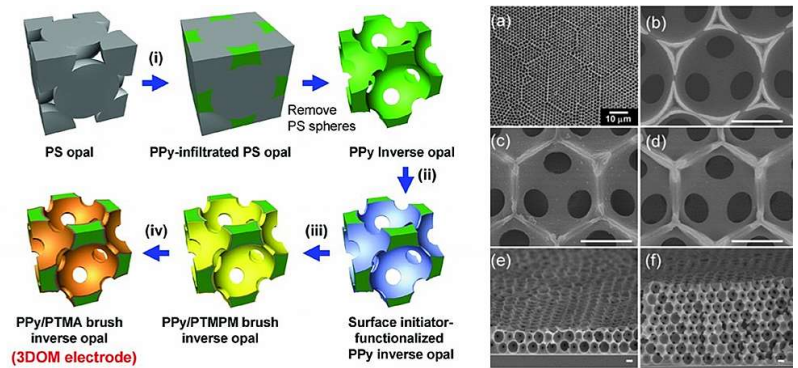

Figure 6: Left) Fabrication process for formation of a three-dimensionally ordered macroporous (3DOM) nitroxide polymer brush cathode. Right) Scanning electron microscope images for the top-view of (a) a PPy inverse opal, (b) a surface initiator-functionalized PPy inverse opal, (c) a PPy/PTMPM brush inverse opal, and (d) a PPy/PTMA brush inverse opal; the cross-section view of PPy/PTMA brush inverse opals with thicknesses of (e) 3.5 and (f) $13.8 \mu \mathrm{m}$. The length of the scale bars in (b) to (f) is $1.0 \mu \mathrm{m}$. Reprinted with permission from ref. [236]. Copyright 2012 John Wiley and Sons.

and 13.8- $\mu \mathrm{m}$ 3DOM electrodes. The thicker $(13.8 \mu \mathrm{m})$ electrode showed a 40-timeshigher discharge capacity compared to a corresponding planar electrode. The authors attributed this to the greater density of poly(TEMPO-methacrylate) in the thicker 3DOM electrode [236]. The cycle life did not deteriorate over 250 cycles for the thinner electrode (yet was not reported for the thicker electrode). Further, the active material loading was not reported, limiting comparisons to other studies. Yet, this study illustrates a viable method of designing thicker porous electrode films using radical and conducting polymers.

\section{Applications}

Radical polymers could potentially be used as the active material in traditional solid electrodes and /or emerging flexible or flow-based electrode designs. They would share many advantages of other organic electronic devices such as organic light-emitting diodes (OLEDs), organic photovoltaics, and organic semiconductors [62]. Additionally, Takahashi et al. suggested that the electrochromic-nature of some radical polymers along with their charge-storing capability could enable the design of battery-like display devices [237]. These potential advantages include easy processing and manufacturing, chemical tunability, and environmentally-benign character, in addition to desirable electronic and electrochemical properties. Despite these potential advantages, radicalbased batteries are not yet economically competitive with traditional battery chemistries for most applications, and are more suitable for applications that require high power densities as well as thin, flexible designs.

\subsection{Solid batteries}

Radical polymer electrodes can be used in particular and complementary applications to Li-ion batteries [59]. While radical polymers are not yet competitive with 
traditional battery chemistries, they are theoretically capable of achieving similar performance. Figure 7 illustrates the approximate energy and power density possibly achievable by radical-bearing polymer batteries relative to other rechargeable battery chemistries, per battery pack weight. The values are converted to a battery weight basis by assuming that the total battery weight is three times that of the active material. This analysis assumes a "best case" optimized cell design that has not yet been achieved for radical polymers. Furthermore, Table 2 further illustrates the high energy density and power density of conducting polymers and radical-bearing polymers. Under the right conditions, radical-bearing polymers can have similar or better energy and power density than some commercialized chemistries.

Table 2: Approximate energy and power density of conducting polymers. The values are per mass active material, and for the conducting polymers include doping ions.

\begin{tabular}{cccc}
\hline Polymer & Specific Energy $(\mathbf{W h} / \mathbf{k g})$ & Specific Power $(\mathbf{W} / \mathbf{k g})$ & Ref. \\
\hline polyacetylene & $10-270$ & $1 \times 10^{1}-3 \times 10^{4}$ & {$[91]$} \\
polyaniline & $20-539$ & $10^{4}-10^{8}$ & {$[91]$} \\
polypyrrole & $20-390$ & $10^{4}-10^{8}$ & {$[91]$} \\
polythiophene & $57-326$ & $3 \times 10^{4}-3 \times 10^{6}$ & {$[91]$} \\
polyphenylene & $49-570$ & $2 \times 10^{2}-3 \times 10^{2}$ & {$[91]$} \\
radical-bearing polymer & $80-400$ & $6 \times 10^{1}-2 \times 10^{4}$ & Figure 7 \\
\hline
\end{tabular}

Yet, to be competitive, radical-polymer-based electrodes need further research to transition beyond their current thin-film and low-polymer-fraction designs. If radicalpolymer-based batteries can become competitive with Li-ion batteries, they could be considered for use in electrical vehicles and mobile electronic devices, which represent large markets for batteries. Nevertheless, the current cost of the polymer and radical materials can be high because they are frequently based on specialty rather than commodity chemicals. Thus, cost remains a significant challenge to their commercialization, but one that may be overcome through economies of scale. A novel complementary approach using current Li-ion batteries is a hybrid supercapacitor-battery design. Vlad et al. combined poly(TEMPO-methacrylate) and $\mathrm{LiFePO}_{4}$ within the same electrode. They showed the polymer facilitated the charging process and relaxed to charge the $\mathrm{LiFePO}_{4}$, thus enabling both higher energy and power densities [121].

\subsection{Redox flow batteries}

Recently, redox flow batteries (RFBs) or regenerative fuel cells have emerged as promising candidates for grid-scale energy storage [238-244]. Organic materials have been investigated for both aqueous and non-aqueous systems. Aqueous systems provide higher power density, use lower cost electrolytes, and are further developed. Yet, they are limited by the smaller electrochemical stability window of water [245, 246]. Non-aqueous systems could offer higher energy density (due to wider electrochemical stability of organic solvents), but are less-developed and require more expensive solvents, salts, and redox-active material $[245,246]$. In the case of either solvent system, the inclusion of redox-active organic molecules in place of inorganics would be in the hope of accruing the previously mentioned benefits of chemical flexibility and sustainability. A number of solution-phase organic materials have been investigated using aqueous 


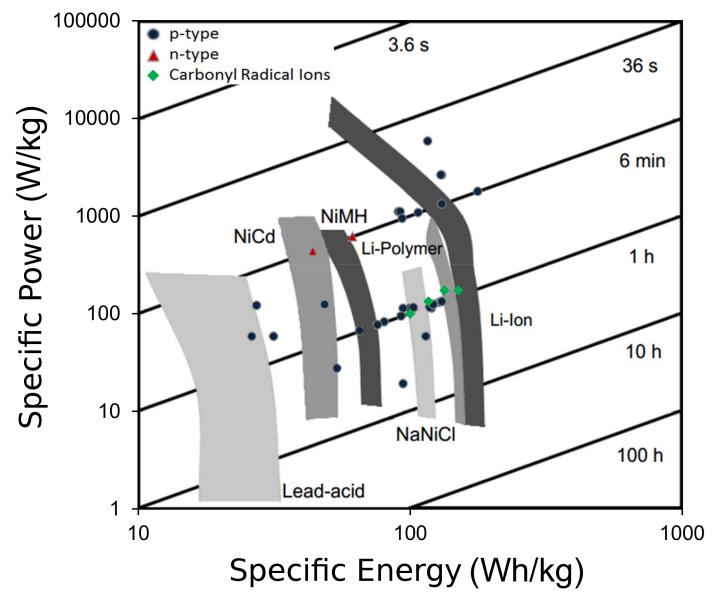

Figure 7: Approximate Ragone plot of radical-bearing polymer cells per estimated battery weight (using achieved capacities and voltages vs. $\mathrm{Li}^{2} / \mathrm{Li}^{+}$) relative to other rechargeable battery chemistries (based on ref. [150]). The carbonyl radical ions data is also per estimated battery weight (original data is from ref. [35]). The regions represent the range of achievable energy and power densities for specific commercial battery chemistries while the points represent the potentially achievable energy and power densities for particular radical polymer or carbonyl chemistries. (To convert potentials relative to a lithium reference electrode, the following conversions were used: $\mathrm{Fc} / \mathrm{Fc}^{+}$is $3.23 \mathrm{~V}$ below $\mathrm{Li} / \mathrm{Li}^{+}[147]$ and $\mathrm{Ag} / \mathrm{Ag}^{+}$is $2.87 \mathrm{~V}$ below $\left.\mathrm{Li} / \mathrm{Li}^{+}[92,99,117,148].\right)$ 
and non-aqueous conditions with the majority of the reports focusing on carbonyl compounds (i.e., quinones), [247-254], discrete radical nitroxides [14, 21, 255, 256], phenothiazines [257, 258], and substituted alkoxybenzenes [15, 259, 260].

Despite their considerable promise, redox-active organic molecules (including discrete radicals) must overcome a number of key challenges related to an intended application in flow batteries, namely cost, low energy densities, transport limitations, and stability. For aqueous systems, the typical low voltage and thus energy density is a key challenge, while for non-aqueous systems the cost of solvents, salts, and redoxactive material is significant [245, 246]. In both systems, charge-transport mechanisms, deleterious side reactions, species crossover, and active material/electrolyte interactions are not necesserily well understood. Expensive separators are often required [11, 246]. Given the electrolyte cost in non-aqueous systems, high concentrations (1-2 M) are required to achieve charge storage capacities necessary for economic viability, and for many redox/solvent combinations this level of solubility is difficult to achieve [244246, 256]. Also, for discrete radicals, high-potential redox events are generally p-type (reductive redox reactions upon discharge) requiring that the electrolyte function as a source of counter-ions.

In the last few years, several groups have investigated polymer-based RFBs [229, 261-265]. One potential advantage of polymer-based RFBs is reduced crossover through the separator, owing to the large polymer size, which would permit the use of cheaper and more porous (i.e., not ion-selective) separators. Notably, the Schubert group reported several TEMPO-based flow batteries [261-263]. They synthesized copolymer poly(TEMPO-methacrylate) and poly(styrene), and created a micellar structured catholyte (micelle size: 50 and $75 \mathrm{~nm}$ diameter). This positive electrolyte was used in a polymer/zinc hybrid flow battery and showed $95 \%$ capacity retention after 1000 cycles [262] (see Figure 8). Notable benefits to this flow cell design include reduced viscosity of the micellar structured positive electrolyte compared to other copolymers, and the improved micelle solubility after charging due to the positively charged corona. Another study investigated a TEMPO-based copolymer (i.e., non-micellar)/zinc flow battery. This chemistry is intended to avoid issue with high-cost and toxic materials in traditional flow batteries [263]. The study investigated both aqueous and non-aqueous flow batteries, and demonstrated good stability ( $>80 \%$ capacity retention) over 500 1000 cycles. This system achieved an energy density of $8.1 \mathrm{Wh} / \mathrm{L}$ and $5-16 \mathrm{Wh} / \mathrm{L}$ for non-aqueous and aqueous electrolytes, respectively.

Sukegawa et al. made a preliminary poly(norbornene)/poly(TEMPO-methacrylate)based flow battery that achieved $95 \%$ of its theoretical charge capacity. Notably, the large size of the polymers prevented their crossover through the separator ( $1 \%$ crossover) [229]. The Rodríguez-López group showed that poly(vinylbenzyl ethyl-viologen) can achieve two important benchmarks for flow batteries: high concentration (1-2 M) and minimized crossover [264]. They demonstrated that above a polymer size/pore size ratio of 0.3 , the crossover is significantly reduce and at best may be decreased to $7 \%$ crossover (compared to $12 \%$ in typical vanadium flow batteries). More recently, the RodríguezLópez group highlighted the ability of polymers to translate small molecule redox properties into nanostructures whose large morphologies exhibit interesting ensemble charge-transport and solution behavior [265]. Overall, the field of RFBs has been dominated by inorganic species, though small organic molecules are now an emerging 


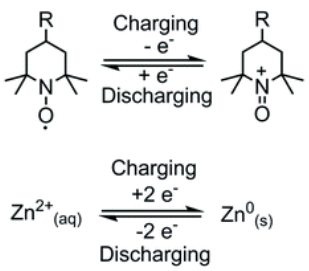

b

alternative. These studies highlight the compelling idea of going a step further and developing soluble polymers for RFB systems.

\section{Conclusions and Future Work}

The field of organic radical polymers provides a broad design space due to the tunability of relevant properties via modifications of both the redox-active radicals and surrounding polymer structure. This review seeks to highlight recent developments in electrochemical energy storage based on organic radical polymers, current challenges, and promising approaches to improved electrode design. Though organic electrodes were initially investigated almost 50 years ago, small-molecule-based organic batteries are experiencing a resurgence based on new high-capacity redox molecules, which are less soluble in common electrolytes, and new applications which leverage the solubility of small organics in common battery electrolytes. Organic radical polymers, particularly those employing TEMPO units, have been most extensively developed, and the primary 
focus of recent work has been optimizing electrode development to maximize practical energy density without sacrificing power performance. Organic radical polymers offer promising performance (as shown in Figure 7) and have many challenges (e.g., electrode conductivity) in common with other organic-based batteries. As a result, the lessons learned from engineering organic radical polymer-based electrodes can inform, and hopefully accelerate, parallel, emerging efforts in the development of small molecule organic-based electrodes.

Theoretical energy densities indicate the potential of radical polymers to compete with Li-ion and other commercialized rechargeable battery chemistries for energy storage applications. Nevertheless, design improvements are required for radical polymer electrodes to begin to approach their theoretical potentials and capacities. These electrode design improvements include both bulk parameters (composition and thickness) and microstructure design parameters (conductive networks and binding method). Such parameters determine the reaction rates as well as electronic and ionic transport processes, which ultimately control the degree to which theoretical cell performance can be achieved. Additionally, the effects of various processing parameters on the electrode microstructure are relatively unexplored. Given this enormous design space, improved structure-property-processing-performance relationships for radical polymers, via systematic experimentation and modeling are critical to evaluate and optimize their design and development.

Advances in the science and engineering of organic-based solid electrodes are required to overcome the low electronic conductivity and mass density of active materials, and achieve the low-cost high-charge-storage-capacity promise of organic-based electrodes. At present most organic electrodes require large amounts of conductive additives (30-80 wt $\%$ ) to provide electronic percolation and enable high-rate devices $[11,128]$. Improvements to electrode fabrication procedures (e.g., ball-milling, solutionprocessing), increased active species conductivity and the use of carbon nanostructures (e.g., graphene) can reduce required carbon loadings and enhance practical performance $[35,266,267]$. Regarding ionic conductivity, the effects of different electrolytes (both solvents and salts) on the behavior of radical polymer electrodes has yet to be systematically investigated. Furthermore, improved understanding of ionic and electronic charge-transfer mechanisms within organic polymers and organic-based electrodes may enable improved power performance of sluggish materials [268-270]. Note that the effect of temperature on performance is yet another under-explored parameter, knowledge of which is essential for successful applications in devices.

Typically Li-ion batteries employing organic positive electrodes use Li metal, which has unresolved challenges due to reactivity with electrolytes and dendrite formation that hinder its use in practical rechargeable batteries [271-274]. Nevertheless, Li-S and Li$\mathrm{O}_{2}$ cells face similar challenges, and significant efforts have been focused on developing safe and stable metal electrodes [275-277]. On the other hand, the electrolyte can be used as an alternative ion source, but this may restrict both cell design and performance as enough electrolyte would be needed to fully-charge both electrodes and maintain acceptable conductivity.

Though in their infancy, emerging redox flow batteries hold promise as low-cost storage options for the grid [14, 15, 241, 245]. However, significant research efforts are required before low-cost systems can be considered commercially viable technology for 
wide deployment. Specifically while leveraging the wider window of electrochemical stability afforded by non-aqueous electrolytes, active species must dissolve and remain stable in electrolytes at high concentrations. To date, few studies have focused on maximizing solubility or investigating the electrochemical behavior of high-capacity organic redox electrolytes [278]. With high concentrations of salt and electroactive species (and thus capacities), non-aqueous solvents generally have diminished conductivity and increased viscosity, requiring design trade-offs. In addition, multi-electron transfer reactions are necessary for organic compounds to realistically surpass and replace inorganic compounds. These demands necessitate advances in the design and engineering of electroreactors for acceptable power delivery. Polymer-based, include conducting polymer, flow battery may provide promising avenue to overcome current challenges in the field, namely poor electronic conducting, low energy density, and significant separator crossover [265, 279]. Nevertheless, polymer RFBs are not without challenges, including lower gravimetric capacity and complex solution behavior (e.g., viscosity, adsorption onto the electrode).

To date, the majority of research on organic-based batteries has been experimental rather than computationally focused. For instance, most optimization approaches have been Edisonian and based on previously identified molecular structures and other naturally-occurring molecules. Nevertheless, computational experience with other battery chemistries and technologies can be leveraged in this field [280-282]. For example, molecular dynamics simulations could be used to understand and explore mechanisms of charge transport in radical polymer electrodes. A wide range of theoretical approaches on different length scales are possible, including molecular, mesoscopic, and full-cell models. Such modeling efforts may be used to guide design, improve performance, and control the operation of organic-based batteries.

The introduction of high-throughput "genomic" theoretical screening techniques may accelerate the discovery of novel organic materials with favorable property sets, similar to the Materials Project for inorganic compounds for Li-ion batteries [283]. Already, combined electrochemical and computational studies have been employed to great effect in investigation of a number of promising organic storage materials [284286]. To ensure the accuracy of these computationally-driven screening methodologies, key descriptors must be determined from systematic investigation of structure-function relationships [35].

Finally, to fully realize the value proposition of "green" batteries based on organic materials detailed techno-economic and lifecycle analyses will be required including the development of scalable and cost-effective synthesis procedures based on abundant raw materials and with minimal waste generation.

\section{Acknowledgment}

We acknowledge financial support by MIT and BYU. The U.S. Department of Energy also provided partial support through two programs: the Joint Center for Energy Storage Research, an Energy Innovation Hub funded by the Office of Science, and the BMR program funded by the Office of Vehicle Technologies. FRB is also grateful to Dr. Jack Vaughey and Dr. Kevin Gallagher of Argonne National Laboratory for stimulating discussions. The authors declare no competing financial interests. 


\section{Supporting Information}

Numerous tables are provided reporting electrochemical properties for conducting polymer conductivity and doping levels, electrode properties and performance of radical polymers. 


\section{References}

[1] J. Eyer, G. Corey, Sandia Report SAND2010-0815. Energy Storage for the Electricity Grid: Benefits and Market Potential Assessment Guide, Sandia National Laboratories, 2010.

[2] H. Ibrahim, A. Ilinca, J. Perron, Energy storage systems-Characteristics and comparisons, Renew. Sust. Energ. Rev. 12 (5) (2008) 1221-1250.

[3] Z. Yang, J. Zhang, M. C. W. Kintner-Meyer, X. Lu, D. Choi, J. P. Lemmon, J. Liu, Electrochemical Energy Storage for Green Grid, Chem. Rev. 111 (5) (2011) 3577-3613.

[4] M. M. Thackeray, C. Wolverton, E. D. Isaacs, Electrical energy storage for transportation-approaching the limits of, and going beyond, lithium-ion batteries, Energy Environ. Sci. 5 (2012) 7854-7863.

[5] H. Chen, T. N. Cong, W. Yang, C. Tan, Y. Li, Y. Ding, Progress in electrical energy storage system: A critical review, Prog. Nat. Sci. 19 (3) (2009) 291-312.

[6] B. Scrosati, J. Garche, Lithium batteries: Status, prospects and future, J. Power Sources 195 (9) (2010) 2419-2430.

[7] B. Dunn, H. Kamath, J.-M. Tarascon, Electrical Energy Storage for the Grid: A Battery of Choices, Science 334 (6058) (2011) 928-935.

[8] D. Rastler, Electricity Energy Storage Options: A White Paper Primer on Applications, Costs and Benefits. (Technical Update 1020676), EPRI, 2010.

[9] J. Cho, S. Jeong, Y. Kim, Commercial and research battery technologies for electrical energy storage applications, Prog. Energy Combust. Sci. 48 (2015) 84-101.

[10] K. Nakahara, K. Oyaizu, H. Nishide, Organic Radical Battery Approaching Practical Use, Chem. Lett. 40 (3) (2011) 222-227.

[11] Y. Liang, Z. Tao, J. Chen, Organic Electrode Materials for Rechargeable Lithium Batteries, Adv. Energy Mater. 2 (2012) 742-769.

[12] M. Armand, S. Grugeon, H. Vezin, S. Laruelle, P. Ribiere, P. Poizot, J.-M. Tarascon, Conjugated dicarboxylate anodes for Li-ion batteries, Nat. Mater. 8 (2009) 120-125.

[13] Y. Morita, S. Nishida, T. Murata, M. Moriguchi, A. Ueda, M. Satoh, K. Arifuku, K. Sato, T. Takui, Organic tailored batteries materials using stable open-shell molecules with degenerate frontier orbitals, Nat. Mater. 10 (2011) 947-951.

[14] Z. Li, S. Li, S. Liu, K. Huang, D. Fang, F. Wang, S. Peng, Electrochemical Properties of an All-Organic Redox Flow Battery Using 2,2,6,6-Tetramethyl-1Piperidinyloxy and N-methylphthalimide, Electrochem. Solid-State Lett. 14 (12) (2011) A171-A173.

[15] F. R. Brushett, J. T. Vaughey, A. N. Jansen, An All-Organic Non-aqueous LithiumIon Redox Flow Battery, Adv. Energy Mater. 2 (2012) 1390-1396.

[16] T. Suga, H. Nishide, Redox-Active Radical Polymers for a Totally Organic Rechargeable Battery, chap. 3, American Chemical Society, 45-53, 2012.

[17] S. Muench, A. Wild, C. Friebe, B. Häupler, T. Janoschka, U. S. Schubert, PolymerBased Organic Batteries, Chem. Rev. 116 (16) (2016) 9438-9484.

[18] R. Hicks (Ed.), Stable Radicals: Fundamentals and Applied Aspects of OddElectron Compounds, John Wiley \& Sons, Inc., 2011. 
[19] N. G. Connelly, W. E. Geiger, Chemical Redox Agents for Organometallic Chemistry, Chem. Rev. 96 (1996) 877-910.

[20] R. G. Hicks, What's new in stable radical chemistry?, Org. Biomol. Chem. 5 (9) (2007) 1321-1338.

[21] C. Buhrmester, L. M. Moshurchak, R. L. Wang, J. R. Dahn, The Use of 2,2,6,6Tetramethylpiperinyl-Oxides and Derivatives for Redox Shuttle Additives in Li-Ion Cells, J. Electrochem. Soc. 153 (10) (2006) A1800-A1804.

[22] M. Armand, J. Tarascon, Building better batteries, Nature 451 (2008) 652-657.

[23] P. Poizot, F. Dolhem, Clean energy new deal for a sustainable world: from non-CO2 generating energy sources to greener electrochemical storage devices, Energy Environ. Sci. 4 (6) (2011) 2003-2019.

[24] S. Renault, S. Gottis, A.-L. Barres, M. Courty, O. Chauvet, F. Dolhem, P. Poizot, A green Li-organic battery working as a fuel cell in case of emergency, Energy Environ. Sci. 6 (2013) 2124-2133.

[25] S. Gottis, A.-L. Barrés, F. Dolhem, P. Poizot, Voltage Gain in Lithiated EnolateBased Organic Cathode Materials by Isomeric Effect, ACS Appl. Mater. Interfaces 6 (14) (2014) 10870-10876.

[26] H. Nishide, K. Oyaizu, Toward Flexible Batteries, Science 319 (2008) 737-738.

[27] Y.-H. Huang, J. B. Goodenough, High-Rate $\mathrm{LiFePO}_{4}$ Lithium Rechargeable Battery Promoted by Electrochemically Active Polymers, Chem. Mater. 20 (23) (2008) 7237-7241.

[28] N. Casado, G. Hernández, A. Veloso, S. Devaraj, D. Mecerreyes, M. Armand, PEDOT Radical Polymer with Synergetic Redox and Electrical Properties, ACS Macro Lett. 5 (1) (2016) 59-64.

[29] P. D. Frischmann, Y. Hwa, E. J. Cairns, B. A. Helms, Redox-Active Supramolecular Polymer Binders for Lithium-Sulfur Batteries That Adapt Their Transport Properties in Operando, Chem. Mater. 28 (20) (2016) 7414-7421.

[30] H. Alt, H. Binder, A. Kahling, G. Sandstede, Investigation into the use of quinone compounds-for battery cathodes, Electrochim. Acta 17 (5) (1972) 873-887.

[31] T. Boschi, R. Pappa, G. Pistoia, M. Tocci, On the Use of Nonylbenzo-hexaquinone as a substitute for monomeric quinones in non-aqueous cells, J. Electroanal. Chem. 176 (1984) 235-242.

[32] M. Pasquali, G. Pistoia, T. Boschi, P. Tagliatesta, Redox mechanism and cycling behavior of nonylbenzo-hexaquinone electrode in Li Cells, Solid State Ionics 23 (1987) 261-266.

[33] M. Yao, H. Senoh, S.-i. Yamazaki, Z. Siroma, T. Sakai, K. Yasuda, High-capacity organic positive-electrode material based on a benzoquinone derivative for use in rechargeable lithium batteries, J. Power Sources 195 (24) (2010) 8336-8340.

[34] W. Wang, W. Xu, L. Cosimbescu, D. Choi, L. Li, Z. Yang, Anthraquinone with tailored structure for a nonaqueous metal-organic redox flow battery, Chem. Commun. 48 (53) (2012) 6669-6671.

[35] Y. Liang, P. Zhang, S. Yang, Z. Tao, J. Chen, Fused Heteroaromatic Organic Compounds for High-Power Electrodes of Rechargeable Lithium Batteries, Adv. Energy Mater. 3 (5) (2013) 600-605.

[36] K. Motokuni, B. Häupler, R. Burges, M. D. Hager, U. S. Schubert, Synthesis and electrochemical properties of novel redox-active polymers with anthraquinone 
moieties by Pd-catalyzed cyclopolymerization of dienes, J. Polym. Sci. A Polym. Chem. 54 (14) (2016) 2184-2190.

[37] J. Geng, J.-P. Bonnet, S. Renault, F. Dolhem, P. Poizot, Evaluation of polyketones with $\mathrm{N}$-cyclic structure as electrode material for electrochemical energy storage: case of tetraketopiperazine unit, Energy Environ. Sci. 3 (2010) 1929-1933.

[38] S. Renault, J. Geng, F. Dolhem, P. Poizot, Evaluation of polyketones with Ncyclic structure as electrode material for electrochemical energy storage: case of pyromellitic diimide dilithium salt, Chem. Commun. 47 (8) (2011) 2414-1416.

[39] M. Yao, M. Araki, H. Senoh, S.-I. Yamazaki, T. Sakai, K. Yasuda, Indigo Dye as a Positive-electrode Material for Rechargeable Lithium Batteries, Chem. Lett. 39 (9) (2010) 950-952.

[40] A. Viehbeck, M. J. Goldberg, C. A. Kovac, Electrochemical Properties of Polyimides and Related Imide Compounds, J. Electrochem. Soc. 137 (5) (1990) 1460-1466.

[41] D. J. Kim, S. H. Je, S. Sampath, J. W. Choi, A. Coskun, Effect of N-substitution in naphthalenediimides on the electrochemical performance of organic rechargeable batteries, R. Soc. Chem. Adv. 2 (2012) 7968-7970.

[42] S. Renault, V. A. Mihali, K. Edström, D. Brandell, Stability of organic Naion battery electrode materials: The case of disodium pyromellitic diimidate, Electrochem. Commun. 45 (2014) 52-55.

[43] W. Walker, S. Grugeon, H. Vezin, S. Laruelle, M. Armand, F. Wudl, J.-M. Tarascon, Electrochemical characterization of lithium 4,4'-tolane-dicarboxylate for use as a negative electrode in Li-ion batteries, J. Mater. Chem. 21 (2011) $1615-1620$.

[44] W. Walker, S. Grugeon, H. Vezin, S. Laruelle, M. Armand, J. Tarascon, F. Wudl, The effect of length and cis/trans relationship of conjugated pathway on secondary battery performance in organolithium electrodes, Electrochem. Commun. 12 (10) (2010) 1348-1351.

[45] W. Walker, S. Grugeon, O. Mentre, S. Laruelle, J.-M. Tarascon, F. Wudl, Ethoxycarbonyl-Based Organic Electrode for Li-Batteries, J. Am. Chem. Soc. 132 (18) (2010) 6517-6523.

[46] T. Ohzuku, H. Wakamatsu, Z. Takehara, S. Yoshizawa, Nonaqueous lithium/pyromellitic dianhydride cell, Electrochim. Acta 24 (6) (1979) 723-726.

[47] S. J. Visco, C. C. Mailhe, L. C. De Jonghe, M. B. Armand, A Novel Class of Organosulfur Electrodes for Energy Storage, J. Electrochem. Soc. 136 (3) (1989) 661-664.

[48] S. J. Visco, M. Liu, L. C. De Jonghe, Ambient Temperature High-Rate Lithium/Organosulfur Batteries, J. Electrochem. Soc. 137 (4) (1990) 1191-1192.

[49] T. Tatsuma, T. Sotomura, T. Sato, D. A. Buttry, N. Oyama, DimercaptanPolyaniline Cathodes for Lithium Batteries: Addition of a Polypyrrole Derivative for Rapid Charging, J. Electrochem. Soc. 142 (10) (1995) L182-L184.

[50] G. I. Likhtenstein, J. Yamauchi, S. Nakatsuji, A. I. Smirnov, R. Tamura (Eds.), Nitroxides: Applications in Chemistry, Biomedicine, and Materials Science, Wiley-VCH, Weinheim, Germany, 2008.

[51] Y. Morita, S. Suzuki, K. Sato, T. Takui, Synthetic organic spin chemistry for structurally well-defined open-shell graphene fragments, Nat. Chem. 3 (2011) 
197-204.

[52] S. Nishida, Y. Yamamoto, T. Takui, Y. Morita, Organic Rechargeable Batteries with Tailored Voltage and Cycle Performance, ChemSusChem 6 (5) (2013) 794797.

[53] R. D. Webster, In situ electrochemical-ATR-FTIR spectroscopic studies on solution phase 2,4,6-tri-substituted phenoxyl radicals, Electrochem. Commun. 5 (1) (2003) 6-11.

[54] J. Gilroy, D. McKinnon, B. Koivisto, R. G. Hicks, Electrochemical Studies of Verdazyl Radicals, Org. Lett. 9 (23) (2007) 4837-4840.

[55] Z. Song, H. Zhou, Towards Sustainable and Versatile Energy Storage Devices: An Overview on Organic Electrode Materials, Energy Environ. Sci. 6 (2013) 2280-2301.

[56] T. B. Schon, B. T. McAllister, P.-F. Li, D. S. Seferos, The rise of organic electrode materials for energy storage, Chem. Soc. Rev. 45 (22) (2016) 6345-6404.

[57] D. Larcher, J.-M. Tarascon, Towards greener and more sustainable batteries for electrical energy storage, Nat. Chem. 7 (1) (2015) 19-29.

[58] B. Häupler, A. Wild, U. S. Schubert, Carbonyls: Powerful Organic Materials for Secondary Batteries, Adv. Energy Mat. 5 (11) (2015) 1402034, 1402034.

[59] T. Janoschka, M. D. Hager, U. S. Schubert, Powering up the Future: Radical Polymers for Battery Applications, Adv. Mater. 24 (48) (2012) 6397-6409.

[60] S. Liu, H. Wang, Y. Xing, X. Chu, F. Zhao, E. Tang, TEMPO Functionalized Polymers: Synthesis and Applications, Curr. Org. Chem. 20 (13) (2016) 13891403.

[61] A. J. Wingate, B. W. Boudouris, Recent advances in the syntheses of radicalcontaining macromolecules, J. Polym. Sci. A Polym. Chem 54 (13) (2016) 1875-1894.

[62] E. P. Tomlinson, M. E. Hay, B. W. Boudouris, Radical Polymers and Their Application to Organic Electronic Devices, Macromolecules 47 (18) (2014) 6145-6158.

[63] H. Nishide, T. Suga, Organic Radical Battery, Electrochem. Soc. Interface (2005) 32-36.

[64] H. Nishide, K. Oyaizu, Organic Batteries, Springer New York, 235-246, 2013.

[65] R. Boere, T. Roemmele, Electrochemistry of redox-active Group 15/16 heterocycles, Coord. Chem. Rev. 210 (2000) 369-445.

[66] E. R. Altwicker, The Chemistry of Stable Phenoxy Radicals, Chem. Rev. 67 (5) (1967) 475-531.

[67] R. H. T. A. R. Forrester, J. M. Hay, Organic Chemistry of Stable Free Radicals, Academic Press, London, 1968.

[68] M. Stolar, T. Baumgartner, Organic n-type materials for charge transport and charge storage applications, Phys. Chem. Chem. Phys. 15 (2013) 9007-9024.

[69] Z. Chen, Y. Qin, K. Amine, Redox shuttles for safer lithium-ion batteries, Electrochim. Acta 54 (24) (2009) 5605-5613.

[70] A. Rajca, Organic Diradicals and Polyradicals: From Spin Coupling to Magnetism?, Chem. Rev. 94 (1994) 871-893.

[71] P. Kaszynski, Theoretical Analysis of Heteroaromatic Thioaminyl Radicals. Part 2: A Comparison of Ab Initio and Density Functional Methods in the Description 
of Redox Processes, J. Phys. Chem. A 105 (2001) 7626-7633.

[72] J. Veciana, I. Ratera, Polychlorotriphenylmethyl Radicals: Towards Multifunctional Molecular Materials, chap. 3, John Wiley \& Sons, Ltd, 33-80, 2010.

[73] V. Gamero, D. Velasco, S. Latorre, F. Lopez-Calahorra, E. Brillas, L. Julia, [4(N-Carbazolyl)-2,6-dichlorophenyl]bis(2,4,6-trichlorophenyl)methyl radical an efficient red light-emitting paramagnetic molecule, Tetrahedron Lett. 47 (14) (2006) 2305-2309.

[74] J. Brusso, O. Clements, R. Haddon, M. Itkis, A. Leitch, R. Oakley, R. Reed, J. Richardson, Bistabilities in 1,3,2-dithiazolyl radicals, J. Am. Chem. Soc. 126 (26) (2004) 8256-8265.

[75] D. Velasco, S. Castellanos, M. Lopez, F. Lopez-Calahorra, E. Brillas, L. Julia, Red Organic Light-Emitting Radical Adducts of Carbazole and Tris(2,4,6trichlorotriphenyl)methyl Radical That Exhibit High Thermal Stability and Electrochemical Amphotericity, J. Org. Chem. 72 (20) (2007) 7523-7532.

[76] J. F. W. Keana, Newer aspects of the synthesis and chemistry of nitroxide spin labels, Chem. Rev. 78 (1) (1978) 37-64.

[77] E. Rozanstev, Free Nitroxyl Radicals, Plenum Press, New York, 1970.

[78] G. M. Coppinger, A Stable Phenoxy Radical Inert to Oxygen, J. Am. Chem. Soc. 79 (2) (1957) 501-502.

[79] N. C. Yang, A. J. Castro, Synthesis of a Stable Biradical, J. Am. Chem. Soc. 82 (1960) 6208-6208.

[80] G. Coppinger, A stable phenoxy radical inert to oxygen, Tetrahedron 18 (1) (1962) 61-65.

[81] Y. Morita, S. Nishida, J. Kawai, K. Fukui, S. Nakazawa, K. Sato, D. Shiomi, T. Takui, K. Nakasuji, Redox-Based Spin Diversity in a 6-Oxophenalenoxyl System: Generation, ESR/ENDOR/TRIPLE, and Theoretical Studies of 2,5,8Tri-tert-butylphenalenyl- 1,6-bis(olate) Salts, Org. Lett. 4 (12) (2002) 1985-1988.

[82] S. D. J. McKinnon, B. O. Patrick, A. B. P. Lever, R. G. Hicks, Verdazyl radicals as redox-active, non-innocent, ligands: contrasting electronic structures as a function of electron-poor and electron-rich ruthenium bis([small beta]-diketonate) co-ligands, Chem. Commun. 46 (2010) 773-775.

[83] G. A. Snook, P. Kao, A. S. Best, Conducting-polymer-based supercapacitor devices and electrodes, J. Power Sources 196 (1) (2011) 1-12.

[84] S. Conte, G. G. Rodriguez-Calero, S. E. Burkhardt, M. A. Lowe, H. D. Abruña, Designing conducting polymer films for electrochemical energy storage technologies, R. Soc. Chem. Adv.. 3 (2013) 1957-1964.

[85] R. Gracia, D. Mecerreyes, Polymers with redox properties: materials for batteries, biosensors and more, Polym. Chem. 4 (2013) 2206-2214.

[86] R. Seeber, F. Terzi, C. Zanardi, Intrinsically Conducting Polymers, in: Functional Materials in Amperometric Sensing, Monographs in Electrochemistry, Springer Berlin Heidelberg, 23-57, 2014.

[87] M. Aydin, B. Esat, C. Kilic, M. E. Koese, A. Ata, F. Yilmaz, A polythiophene derivative bearing TEMPO as a cathode material for rechargeable batteries, Eur. Polym. J. 47 (12) (2011) 2283-2294.

[88] L. Qie, L.-X. Yuan, W.-X. Zhang, W.-M. Chen, Y.-H. Huang, Revisit of Polypyrrole as Cathode Material for Lithium-Ion Battery, J. Electrochem. Soc. 159 (10) 
(2012) A1624-A1629.

[89] J. Heinze, Electronically conducting polymers, in: E. Steckhan (Ed.), Electrochemistry IV, vol. 152 of Topics in Current Chemistry, Springer Berlin / Heidelberg, 1-47, 1990.

[90] J. Heinze, B. A. Frontana-Uribe, S. Ludwigs, Electrochemistry of Conducting Polymers-Persistent Models and New Concepts, Chem. Rev. 110 (8) (2010) 4724-4771.

[91] P. Novak, K. Mueller, K. Santhanam, O. Haas, Electrochemically Active Polymers for Rechargeable Batteries, Chem. Rev. 97 (1997) 207-282.

[92] K. Oyaizu, T. Suga, K. Yoshimura, H. Nishide, Synthesis and Characterization of Radical-Bearing Polyethers as an Electrode-Active Material for Organic Secondary Batteries, Macromolecules 41 (2008) 6646-6652.

[93] M. Suguro, S. Iwasa, Y. Kusachi, Y. Morioka, K. Nakahara, Cationic Polymerization of Poly(vinyl ether) Bearing a TEMPO Radical: A New Cathode-Active Material for Organic Radical Batteries, Macromol. Rapid Commun. 28 (18-19) (2007) 1929-1933.

[94] S. Yoshihara, H. Isozumi, M. Kasai, H. Yonehara, Y. Ando, K. Oyaizu, H. Nishide, Improving Charge/Discharge Properties of Radical Polymer Electrodes Influenced Strongly by Current Collector/Carbon Fiber Interface, J. Phys. Chem. B 114 (2010) 8335-8340.

[95] S. Yoshihara, H. Katsuta, H. Isozumi, M. Kasai, K. Oyaizu, H. Nishide, Designing current collector/composite electrode interfacial structure of organic radical battery, J. Power Sources 196 (18) (2011) 7806-7811.

[96] T. Suga, H. Konishi, H. Nishide, Photocrosslinked nitroxide polymer cathodeactive materials for application in an organic-based paper battery, Chem. Commun. (Camb.) 7 (17) (2007) 1730-1732.

[97] J. Qu, T. Katsumata, M. Satoh, J. Wada, T. Masuda, Poly(7-oxanorbornenes) carrying 2,2,6,6-tetramethylpiperidine-1-oxy (TEMPO) radicals: Synthesis and charge/discharge properties, Polymer 50 (2) (2009) 391-396.

[98] T. Suga, Y.-J. Pu, S. Kasatori, H. Nishide, Cathode- and Anode-Active Poly(nitroxylstyrene)s for Rechargeable Batteries: p- and n-Type Redox Switching via Substituent Effect, Macromolecules 49 (2007) 3167-3173.

[99] K. Oyaizu, T. Kawamoto, T. Suga, H. Nishide, Synthesis and Charge Transport Properties of Redox-Active Nitroxide Polyethers with Large Site Density, Macromolecules 43 (24) (2010) 10382-10389.

[100] T. Suga, H. Ohshiro, S. Sugita, K. Oyaizu, H. Nishide, Emerging N-Type RedoxActive Radical Polymer for a Totally Organic Polymer-Based Rechargeable Battery, Adv. Mater. 21 (16) (2009) 1627-1630.

[101] A. Q. Contractor, V. A. Juvekar, Elucidation of Band Structure of Charge Storage in Conducting Polymers Using a Redox Reaction, Anal. Chem. 86 (13) (2014) 6323-6330.

[102] J. Huang, J. A. Moore, J. H. Acquaye, R. B. Kaner, Mechanochemical Route to the Conducting Polymer Polyaniline, Macromolecules 38 (2) (2005) 317-321.

[103] Q. Wang, Q. Yao, J. Chang, L. Chen, Enhanced thermoelectric properties of CNT/PANI composite nanofibers by highly orienting the arrangement of polymer chains, J. Mater. Chem. 22 (34) (2012) 17612-17618. 
[104] A. M. Stoneham, M. M. D. Ramos, A. M. Almeida, H. M. G. Correia, R. M. Ribeiro, H. Ness, A. J. Fisher, Understanding electron flow in conducting polymer films: injection, mobility, recombination and mesostructure, J. Phys.: Condens. Matter 14 (42) (2002) 9877-9898.

[105] P. Carbone, A. Troisi, Charge Diffusion in Semiconducting Polymers: Analytical Relation between Polymer Rigidity and Time Scales for Intrachain and Interchain Hopping, J. Phys. Chem. Lett. 5 (15) (2014) 2637-2641.

[106] T. Nagatomo, O. Omoto, Poly(3-methyithiophene) A Stable Cathode-Active Material for Secondary Batteries, J. Electrochem. Soc. 135 (9) (1988) 21242128.

[107] D. MacInnes, M. Druy, P. Nigrey, D. Nairns, A. MacDiarmide, A. Heeger, Organic Batteries: Reversible n- and p-Type Electrochemical Doping of Polyacetylene, (CH)x, J. Chem. Soc. (1981) 317-319.

[108] M. Miyasaka, T. Yamazaki, E. Tsuchida, H. Nishide, Magnetic and electrical properties of poly(3-radical-substituted thiophene)s, Polyhedron 20 (2001) 11571162.

[109] C. DuBois, J. Reynolds, 3,4-Ethylenedioxythiophene-Pyridine-Based Polymers: Redox or n-Type Electronic Conductivity?, Adv. Mater. 14 (24) (2002) 18441846.

[110] G. Inzelt, Rise and rise of conducting polymers, J. Solid State Electrochem. 15 (2011) 1711-1718.

[111] Y. Liang, Z. Chen, Y. Jing, Y. Rong, A. Facchetti, Y. Yao, Heavily n-Dopable $\pi$-Conjugated Redox Polymers with Ultrafast Energy Storage Capability, J. Am. Chem. Soc. 137 (15) (2015) 4956-4959.

[112] Y. Kiya, J. C. Henderson, G. R. Hutchison, H. D. Abruña, Synthesis, computational and electrochemical characterization of a family of functionalized dimercaptothiophenes for potential use as high-energy cathode materials for lithium/lithium-ion batteries, J. Mater. Chem. 17 (41) (2007) 4366-4376.

[113] J. Gao, M. A. Lowe, S. Conte, S. E. Burkhardt, H. D. Abruña, Poly(2,5dimercapto-1,3,4-thiadiazole) as a Cathode for Rechargeable Lithium Batteries with Dramatically Improved Performance, Chem. Eur. J. 18 (27) (2012) 85218526.

[114] S. E. Burkhardt, S. Conte, G. G. Rodríguez-Calero, M. A. Lowe, H. Qian, W. Zhou, J. Gao, R. G. Hennig, H. D. Abruña, Towards organic energy storage: characterization of 2,5-bis(methylthio)thieno[3,2-b]thiophene, J. Mater. Chem. 21 (26) (2011) 9553-9563.

[115] Y.-H. Huang, K.-S. Park, J. B. Goodenough, Improving Lithium Batteries by Tethering Carbon-Coated $\mathrm{LiFePO}_{4}$ to Polypyrrole, J. Electrochem. Soc. 153 (12) (2006) A2282-A2286.

[116] K.-S. Park, S. Schougaard, J. Goodenough, Conducting-Polymer/Iron-RedoxCouple Composite Cathodes for Lithium Secondary Batteries, Adv. Mater. 19 (6) (2007) 848-851.

[117] H. Nishide, S. Iwasa, Y. Pu, T. Suga, K. Nakahara, M. Satoh, Organic radical battery: nitroxide polymers as a cathode-active material, Electrochim. Acta $50(2-3)(2004) 827-831$. 
[118] M. A. Lowe, Y. Kiya, J. C. Henderson, H. D. A. na, Pendant thioether polymer for redox capacitor cathodes, Electrochemistry Communications 13 (5) (2011) $462-465$.

[119] K. Nakahara, J. Iriyama, S. Iwasa, M. Suguro, M. Satoh, E. J. Cairns, Allaminated film packaged organic radical battery for high-power applications, J. Power Sources 163 (2) (2007) 1110-1113.

[120] M. Satoh, Organic Radical Battery and Its Technology, NEC J. of Adv. Tech. 2 (3) (2005) 262-263.

[121] A. Vlad, N. Singh, J. Rolland, S. Melinte, P. M. Ajayan, J.-F. Gohy, Hybrid supercapacitor-battery materials for fast electrochemical charge storage, Sci. Rep. 4 (2014) 4315.

[122] L. Rostro, A. G. Baradwaj, B. W. Boudouris, Controlled Radical Polymerization and Quantification of Solid State Electrical Conductivities of Macromolecules Bearing Pendant Stable Radical Groups, ACS Appl. Mater. Interfaces 5 (20) (2013) 9896-9901.

[123] L. Rostro, S. H. Wong, B. W. Boudouris, Solid State Electrical Conductivity of Radical Polymers as a Function of Pendant Group Oxidation State, Macromolecules 47 (11) (2014) 3713-3719.

[124] C. Karlsson, H. Huang, M. Strømme, A. Gogoll, M. Sjödin, Probing Polymer-Pendant Interactions in the Conducting Redox Polymer Poly(pyrrol-3ylhydroquinone), J. Phys. Chem. C 118 (41) (2014) 23499-23508.

[125] M. Suguro, A. Mori, S. Iwasa, K. Nakahara, K. Nakano, Syntheses and Electrochemical Properties of TEMPO Radical Substituted Silicones: Active Material for Organic Radical Batteries, Macromol. Chem. Phys. 210 (2009) 1402-1407.

[126] M. Satoh, K. Nakahara, J. Iriyama, S. Iwasa, M. Suguro, High Power Organic Radical Battery for Information Systems, IEICE Trans. Electron. E87-C (12) (2004) 2076-2080.

[127] H. Nishide, K. Koshika, K. Oyaizu, Environmentally benign batteries based on organic radical polymers, Pure Appl. Chem. 81 (11) (2009) 1961-1970.

[128] T. Suga, H. Nishide, Rechargeable Batteries Using Robust but Redox Active Organic Radicals, chap. 14, Wiley, 507-519, 2010.

[129] K. Oyaizu, Y. Ando, H. Konishi, H. Nishide, Nernstian Adsorbate-like Bulk Layer of Organic Radical Polymers for High-Density Charge Storage Purposes, J. Am. Chem. Soc. 130 (2008) 14459-14461.

[130] E. Biçer, A. Öktemer, Preparation and Investigation of a Novel Organic Polymer Consisting of 2,2,6,6-Tetramethylpiperidine-N-oxy as a Cathode Active Material in Li-Ion Batteries, Int. J. Electrochem. (2013) 732749.

[131] T. Katsumata, J. Qu, M. Shiotsuki, M. Satoh, J. Wada, J. Igarashi, K. Mizoguchi, T. Masuda, Synthesis, Characterization, and Charge/Discharge Properties of Polynorbornenes Carrying 2,2,6,6-Tetramethylpiperidine-1-oxy Radicals at Hight Density, Macromolecules 41 (2008) 1175-1183.

[132] T. Katsumata, M. Satoh, J. Wada, M. Shiotsuki, F. Sanda, T. Masuda, Polyacetylene and Polynorbornene Derivatives Carrying TEMPO. Synthesis and Properties as Organic Radical Battery Materials, Macromol. Rapid Commun. 27 (15) (2006) 1206-1211. 
[133] H. A. López-Peña, L. S. Hernández-Muñoz, J. Cardoso, F. J. González, I. González, C. Frontana, Electrochemical and spectroelectrochemical properties of nitroxyl radical species in PTMA, an organic radical polymer. Influence of the microstructure, Electrochem. Commun. 11 (7) (2009) 1369-1372.

[134] J. Qu, T. Katsumata, M. Satoh, J. Wada, T. Masuda, Synthesis and Properties of Polyacetylene and Polynorbornene Derivatives Carrying 2,2,5,5-Tetramethyl-1pyrrolidinyloxy Moieties, Macromolecules 40 (2007) 3136-3144.

[135] H. A. López-Peña, L. S. Hernández-Muñoz, B. A. Frontana-Uribe, F. J. González, I. González, C. Frontana, J. Cardoso, Tacticity Influence on the Electrochemical Reactivity of Group Transfer Polymerization-Synthesized PTMA, J. Phys. Chem. B 116 (18) (2012) 5542-5550.

[136] T. Janoschka, A. Teichler, B. Häupler, T. Jähnert, M. D. Hager, U. S. Schubert, Reactive Inkjet Printing of Cathodes for Organic Radical Batteries, Adv. Energy Mater. 3 (8) (2013) 1025-1028.

[137] M. Suguro, S. Iwasa, K. Nakahara, Fabrication of a Practical and Polymer-Rich Organic Radical Polymer Electrode and its Rate Dependence, Macromol. Rapid Commun. 29 (20) (2008) 1635-1639.

[138] P. Nesvadba, L. Bugnon, P. Maire, P. Novak, Synthesis of A Novel Spirobisnitroxide Polymer and its Evaluation in an Organic Radical Battery, Chem. Mater. 22 (3) (2010) 783-788.

[139] X. Zhang, H. Li, L. Li, G. Lu, S. Zhang, L. Gu, Y. Xia, X. Huang, Polyallene with pendant nitroxyl radicals, Polymer 49 (16) (2008) 3393-3398.

[140] T. Jähnert, M. D. Hager, U. S. Schubert, Application of phenolic radicals for antioxidants, as active materials in batteries, magnetic materials and ligands for metal-complexes, J. Mater. Chem. A 2 (2014) 15234.

[141] J. Qu, F. Z. Khan, M. Satoh, J. Wada, H. Hayashi, K. Mizoguchi, T. Masuda, Synthesis and charge/discharge properties of cellulose derivatives carrying free radicals, Polymer 49 (6) (2008) 1490-1496.

[142] T. Jähnert, B. Häupler, T. Janoschka, M. D. Hager, U. S. Schubert, Polymers Based on Stable Phenoxyl Radicals for the Use in Organic Radical Batteries, Macromol. Rapid Commun. 35 (9) (2014) 882-887.

[143] T. Jähnert, T. Janoschka, M. D. Hager, U. S. Schubert, Polymers with n-type nitroxide side groups: Synthesis and electrochemical characterization, Eur. Polym. J. 61 (2014) 105-112.

[144] W. Deng, X. Liang, X. Wu, J. Qian, Y. Cao, X. Ai, J. Feng, H. Yang, A low cost, all-organic Na-ion Battery Based on Polymeric Cathode and Anode, Sci. Rep. 3 (2013) 2671.

[145] T. Jähnert, M. D. Hager, U. S. Schubert, Assorted Phenoxyl-Radical Polymers and Their Application in Lithium-Organic Batteries, Macromol. Rapid Commun. 37 (8) (2016) 725-730.

[146] M. Yao, H. Senoh, T. Sakai, T. Kiyobayashi, Redox active poly(N-vinylcarbazole) for use in rechargeable lithium batteries, J. Power Sources 202 (2012) 364-368.

[147] S. Komaba, T. Tanaka, T. Ozeki, T. Taki, H. Watanabe, H. Tachikawa, Fast redox of composite electrode of nitroxide radical polymer and carbon with polyacrylate binder, J. Power Sources 195 (18) (2010) 6212-6217. 
[148] T. Suga, S. Sugita, H. Ohshiro, K. Oyaizu, H. Nishide, p- and n-Type bipolar redox-active radical polymer: Toward totally organic polymer-based rechargeable devices with variable configuration, Adv. Mater. 23 (6) (2011) 751-754.

[149] Y. Takahashi, N. Kijima, K. Tokiwa, T. Watanabe, J. Akimoto, Single-crystal synthesis, structure refinement and electrical properties of $\mathrm{Li}_{0.5} \mathrm{CoO}_{2}$, J. Phys.: Condens. Matter 19 (43) (2007) 436202.

[150] P. V. den Bossche, F. Vergels, J. V. Mierlo, J. Matheys, W. V. Autenboer, SUBAT: An assessment of sustainable battery technology, J. Power Sources 162 (2) (2006) 913-919.

[151] F. Li, Y. Zhang, S. R. Kwon, J. L. Lutkenhaus, Electropolymerized Polythiophenes Bearing Pendant Nitroxide Radicals, ACS Macro Lett. 5 (3) (2016) 337-341.

[152] S. Sen, J. Saraidaridis, S. Y. Kim, G. T. R. Palmore, Viologens as Charge Carriers in a Polymer-Based Battery Anode, ACS Appl. Mater. Inter. 5 (16) (2013) 78257830.

[153] K.-J. Euler, The conductivity of compressed powders. A review, J. Power Sources 3 (2) (1978) 117-136.

[154] W. Lu, D. Chung, A comparative study of carbons for use as an electrically conducting additive in the manganese dioxide cathode of an electrochemical cell, Carbon 40 (3) (2002) 447-449.

[155] A. Urfer, G. Lawrance, D. Swinkels, The role of particle size in cathode optimization in alkaline primary batteries, J. Appl. Electrochem. 31 (2001) 341-347.

[156] M. Wissler, Graphite and carbon powders for electrochemical applications, J. Power Sources 156 (2) (2006) 142-150.

[157] S. Kuroda, N. Tobori, M. Sakuraba, Y. Sato, Charge-discharge properties of a cathode prepared with ketjen black as the electro-conductive additive in lithium ion batteries, J. Power Sources 119-121 (2003) 924-928.

[158] J. K. Hong, J. H. Lee, S. M. Oh, Effect of carbon additive on electrochemical performance of $\mathrm{LiCoO}_{2}$ composite cathodes, J. Power Sources 111 (1) (2002) 90-96.

[159] G. Wang, J. Ahn, J. Yao, M. Lindsay, H. Liu, S. Dou, Preparation and characterization of carbon nanotubes for energy storage, J. Power Sources 119-121 (2003) $16-23$.

[160] K. Nakahara, J. Iriyama, S. Iwasa, M. Suguro, M. Satoh, E. J. Cairns, Cell properties for modified PTMA cathodes of organic radical batteries, J. Power Sources 165 (1) (2007) 398-402.

[161] M. L. Clingerman, Development and Modeling of Electrically Conductive Composite Materials, Ph.D. thesis, Michigan Technological Univeristy, 1998.

[162] K. Nakahara, S. Iwasa, M. Satoh, Y. Morioka, J. Iriyama, M. Suguro, E. Hasegawa, Rechargeable batteries with organic radical cathodes, Chem. Phys. Lett. 359 (5-6) (2002) 351-354.

[163] T. Suga, K. Yoshimura, H. Nishide, Nitroxide-Substituted Polyether as a New Material for Batteries, Macromol. Symp. 245-246 (1) (2006) 416-422.

[164] J. Iriyama, K. Nakahara, S. Iwasa, Y. Morioka, M. Suguro, M. Satoh, Synthsis and Electrochemical Characterization of a Polyradical Cathode Material for Rechargeable Batteries, IEICE Trans. Electron. E85-C (6) (2002) 1256-1257. 
[165] L.-F. Deng, X.-H. Li, L.-X. Xiao, Y.-H. Zhang, Synthesis and electrochemical properties of polyradical cathode material for lithium second batteries, J. Cent. South Univ. T 10 (3) (2003) 190-194.

[166] J. Qu, T. Katsumata, M. Satoh, J. Wada, J. Igarashi, K. Mizoguchi, T. Masuda, Synthesis and charge/discharge properties of polyacetylenes carrying 2,2,6,6tetramethyl-1-piperidinoxy radicals, Chem. Eur. J. 13 (28) (2007) 7965-7973.

[167] J. Qu, T. Fujii, T. Katsumata, Y. Suzuki, M. Shiotsuki, F. Sanda, M. Satoh, J. Wada, T. Masuda, Helical polyacetylenes carrying 2,2,6,6-tetramethyl-1piperidinyloxy and 2,2,5,5-tetramethyl-1-pyrrolidinyloxy moieties: Their synthesis, properties, and function, J. Polym. Sci. A Polym. Chem. 45 (23) (2007) 5431-5445.

[168] J.-J. Lu, J.-Q. Ma, J.-M. Yi, Z.-L. Shen, Y.-J. Zhong, C.-A. Ma, M.-C. Li, Electrochemical Polymerization of Pyrrole Containing \{TEMPO\} Side Chain on Pt Electrode and Its Electrochemical Activity, Electrochim. Acta 130 (2014) 412-417.

[169] L. Xu, F. Yang, C. Su, L. Ji, C. Zhang, Synthesis and properties of novel TEMPOcontained polypyrrole derivatives as the cathode material of organic radical battery, Electrochim. Acta 130 (2014) 148-155.

[170] K. Oyaizu, H. Nishide, Radical Polymers for Organic Electronic Devices: A Radical Departure from Conjugated Polymers?, Adv. Mater. 21 (22) (2009) 2339-2344.

[171] J. Kim, G. Cheruvally, J. Choi, J. Ahn, S. Lee, D. Choi, C. Song, Effect of radical polymer cathode thickness on the electrochemical performance of organic radical battery, Solid State Ionics 178 (27-28) (2007) 1546-1551.

[172] K.-A. Seid, J.-C. Badot, C. Perca, O. Dubrunfaut, P. Soudan, D. Guyomard, B. Lestriez, An In Situ Multiscale Study of Ion and Electron Motion in a LithiumIon Battery Composite Electrode, Adv. Energy Mater. (2015) 1400903.

[173] J.-K. Kim, G. Cheruvally, J.-W. Choi, J.-H. Ahn, D. S. Choi, C. E. Song, Rechargeable Organic Radical Battery with Electrospun, Fibrous MembraneBased Polymer Electrolyte, J. Electrochem. Soc. 154 (9) (2007) A839-A843.

[174] J.-K. Kim, J.-H. Ahn, G. Cheruvally, G. S. Chauhan, J.-W. Choi, D.-S. Kim, H.-J. Ahn, S.-H. Lee, C. E. Song, Electrochemical Properties of Rechargeable Organic Radical Battery with PTMA Cathode, Met. Mater. Int. 15 (1) (2009) 77-82.

[175] M. Winter, R. J. Brodd, What Are Batteries, Fuel Cells, and Supercapacitors?, Chem. Rev. 104 (10) (2004) 4245-4269.

[176] D. E. Stephenson, Microstructure and Transport Properties of Porous Li-Ion Electrodes, Ph.D. thesis, Brigham Young University, 2011.

[177] A. G. Baradwaj, S. H. Wong, J. S. Laster, A. J. Wingate, M. E. Hay, B. W. Boudouris, Impact of the Addition of Redox-Active Salts on the Charge Transport Ability of Radical Polymer Thin Films, Macromolecules 49 (13) (2016) 47844791.

[178] K. Kinoshita, Carbon: Electrochemical and physicochemical properties, Wiley, 1988.

[179] S. Mandal, J. M. Amarilla, J. Ibez, J. M. Rojo, The Role of Carbon Black in LiMn2O4-Based Composites as Cathodes for Rechargeable Lithium Batteries, J. Electrochem. Soc. 148 (1) (2001) A24-A29. 
[180] K. Xu, Nonaqueous Liquid Electrolytes for Lithium-Based Rechargeable Batteries, Chem. Rev. 104 (10) (2004) 4303-4418.

[181] G. Chen, W. Weng, D. Wu, C. Wu, PMMA/graphite nanosheets composite and its conducting properties, Eur. Polym. J. 39 (12) (2003) 2329-2335.

[182] J. J. Andrade, A. Auto, Y. Kobayashi, Y. Shibusa, K. Shirane, Percolation conduction in vapour grown carbon fibre, Physica A 248 (3-4) (1998) 227-234.

[183] I. V. Thorat, V. Mathur, J. N. Harb, D. R. Wheeler, Performance of carbon-fibercontaining $\mathrm{LiFePO}_{4}$ cathodes for high-power applications, J. Power Sources 162 (1) (2006) 673-678.

[184] J.-Y. Huot, 24th International Battery Seminar 0026; Exhibit Roles of carbon materials in modern power sources, Tech. Rep., 2007.

[185] G. Wang, Z. Shao, Z. Yu, Comparisons of different carbon conductive additives on the electrochemical performance of activated carbon, Nanotechnology 18 (2007) 205705.

[186] Q. Lin, J. N. Harb, Implementation of a Thick-Film Composite Li-Ion Microcathode Using Carbon Nanotubes as the Conductive Filler, J. Electrochem. Soc. 151 (8) (2004) A1115-A1119.

[187] J.-K. Kim, G. Cheruvally, J.-H. Ahn, Y.-G. Seo, D. S. Choi, S.-H. Lee, C. E. Song, Organic radical battery with PTMA cathode: Effect of PTMA content on electrochemical properties, J. Ind. Eng. Chem. 14 (3) (2008) 371-376.

[188] W. Guo, Y.-X. Yin, S. Xin, Y.-G. Guo, L.-J. Wan, Superior radical polymer cathode material with a two-electron process redox reaction promoted by graphene, Energy Environ. Sci. 5 (1) (2012) 5221-5225.

[189] K. Nakahara, J. Iriyama, S. Iwasa, M. Suguro, M. Satoh, E. J. Cairns, High-rate capable organic radical cathodes for lithium rechargeable batteries, J. Power Sources 165 (2) (2007) 870-873.

[190] W. Choi, S. Ohtani, K. Oyaizu, H. Nishide, K. E. Geckeler, Radical PolymerWrapped SWNTs at a Molecular Level: High-Rate Redox Mediation Through a Percolation Network for a Transparent Charge-Storage Material, Adv. Mater. 23 (38) (2011) 4440-4443.

[191] K. Oyaizu, H. Tatsuhira, H. Nishide, Facile charge transport and storage by a TEMPO-populated redox mediating polymer integrated with polyaniline as electrical conducting path, Polym. J. (2015) 212-219.

[192] A. Stein, Z. Wang, M. A. Fierke, Functionalization of Porous Carbon Materials with Designed Pore Architecture, Adv. Mater. 21 (3) (2009) 265-293.

[193] M. C. Iovu, R. Zhang, J. R. Cooper, D. M. Smilgies, A. E. Javier, E. E. Sheina, T. Kowalewski, R. D. McCullough, Conducting Block Copolymers of Regioregular Poly(3-hexylthiophene) and Poly(methacrylates): Electronic Materials with Variable Conductivities and Degrees of Interfibrillar Order, Macromol. Rapid Commun. 28 (17) (2007) 1816-1824.

[194] G. Hauffman, J. Rolland, J.-P. Bourgeois, A. Vlad, J.-F. Gohy, Synthesis of nitroxide-containing block copolymers for the formation of organic cathodes, J. Polym. Sci. A Polym. Chem. 51 (1) (2013) 101-108.

[195] G. Hauffman, Q. Maguin, J.-P. Bourgeois, A. Vlad, J.-F. Gohy, Micellar Cathodes from Self-Assembled Nitroxide-Containing Block Copolymers in Battery Electrolytes, Macromol. Rapid Commun. 35 (2) (2014) 228-233. 
[196] G. Teyssedre, C. Laurent, Charge Transport Modeling in Insulating Polymers: From Molecular to Macroscopic Scale, IEEE Trans. Dielectr. Electr. Insul. 12 (5) (2005) 857-875.

[197] V. Ruhle, J. Kirkpatrick, D. Andrienko, A multiscale description of charge transport in conjugated oligomers, J. Chem. Phys. 132 (13) (2010) 134103.

[198] T. W. Kemper, R. E. Larsen, T. Gennett, Relationship between Molecular Structure and Electron Transfer in a Polymeric Nitroxyl-Radical Energy Storage Material, J. Phys. Chem. C 118 (31) (2014) 17213-17220.

[199] I. V. Thorat, D. E. Stephenson, N. A. Zacharias, K. Zaghib, J. N. Harb, D. R. Wheeler, Quantifying tortuosity in porous Li-ion battery materials, J. Power Sources 188 (2) (2009) 592-600.

[200] N. A. Zacharias, D. R. Nevers, C. Skelton, K. Knackstedt, D. E. Stephenson, D. R. Wheeler, Direct Measurements of Effective Ionic Transport in Porous Li-Ion Electrodes, J. Electrochem. Soc. 160 (2) (2013) A306-A311.

[201] G. M. Goldin, A. M. Colclasure, A. H. Wiedemann, R. J. Kee, Three-dimensional particle-resolved models of Li-ion batteries to assist the evaluation of empirical parameters in one-dimensional models, Electrochim. Acta 64 (2012) 118-129.

[202] P. Shearing, N. Brandon, J. Gelb, R. Bradley, P. Withers, A. Marquis, S. Cooper, S. Harris, Multi Length Scale Microstructural Investigations of a Commercially Available Li-Ion Battery Electrode, J. Electrochem. Soc. 159 (7) (2012) A1023A1027.

[203] H. Tokue, K. Oyaizu, T. Sukegawa, H. Nishide, TEMPO/Viologen Electrochemical Heterojunction for Diffusion-Controlled Redox Mediation: A Highly Rectifying Bilayer-Sandwiched Device Based on Cross-Reaction at the Interface between Dissimilar Redox Polymers, ACS Appl. Mater. Inter. 6 (6) (2014) 4043-4049.

[204] C. Liu, F. Li, L.-P. Ma, H.-M. Cheng, Advanced Materials for Energy Storage, Adv. Mater. 22 (8) (2010) E28-E62.

[205] D. Wu, F. Xu, B. Sun, R. Fu, H. He, K. Matyjaszewski, Design and Preparation of Porous Polymers, Chem. Rev. 112 (7) (2012) 3959-4015.

[206] Y. V. Baskakova, O. Yarmolenko, O. Efimov, Polymer gel electrolytes for lithium batteries, Russ. Chem. Rev. 81 (2012) 367-380.

[207] J. W. Long, B. Dunn, D. R. Rolison, H. S. White, Three-Dimensional Battery Architectures, Chem. Rev. 104 (10) (2004) 4463-4492.

[208] C. R. Mulzer, L. Shen, R. P. Bisbey, J. R. McKone, N. Zhang, H. D. Abruña, W. R. Dichtel, Superior Charge Storage and Power Density of a Conducting Polymer-Modified Covalent Organic Framework, ACS Central Science 2 (9) (2016) 667-673.

[209] M. Suguro, S. Iwasa, K. Nakahara, Effect of Ethylene Oxide Structure in TEMPO Polymers on High Rate Discharge Properties, Electrochem. Solid-State Lett. 12 (9) (2009) A194-A197.

[210] Y. Dai, Y. Zhang, L. Gao, G. Xu, J. Xie, A Sodium Ion Based Organic Radical Battery, Electrochem. Solid-State Lett. 13 (3) (2010) A22-A24.

[211] Y.-Y. Cheng, C.-C. Li, J.-T. Lee, Electrochemical behavior of organic radical polymer cathodes in organic radical batteries with N-butyl-N-methylpyrrolidinium bis(trifluoromethylsulfonyl)imide ionic liquid electrolytes, Electrochim. Acta 66 
(2012) 332-339.

[212] M. Park, X. Zhang, M. Chung, G. B. Less, A. M. Sastry, A review of conduction phenomena in Li-ion batteries, J. Power Sources 195 (24) (2010) 7904-7929.

[213] S. H. Lee, J.-K. Kim, G. Cheruvally, J.-W. Choi, J.-H. Ahn, G. S. Chauhan, C. E. Song, Electrochemical properties of new organic radical materials for lithium secondary batteries, J. Power Sources 184 (2) (2008) 503-507.

[214] Y. Dai, Y. Zhang, L. Gao, G. Xu, J. Xie, Electrochemical Performance of Organic Radical Cathode with Ionic Liquid Based Electrolyte, J. Electrochem. Soc. 158 (3) (2011) A291-A295.

[215] T. Suga, Y.-J. Pu, K. Oyaizu, H. Nishide, Electron-Transfer Kinetics of Nitroxide Radicals as an Electrode-Active Material, Bull. Chem. Soc. Jpn. 77 (2004) 22032204.

[216] R. S. Nicholson, Theory and Application of Cyclic Voltammetry for Measurement of Electrode Reaction Kinetics., Anal. Chem. 37 (11) (1965) 1351-1355.

[217] N. G. Tsierkezos, Investigation of the Electrochemical Reduction of Benzophenone in Aprotic Solvents Using the Method of Cyclic Voltammetry, J. Solution Chem. 36 (10) (2007) 1301-1310.

[218] G. Grampp, K. Rasmussen, Solvent dynamical effects on the electron selfexchange rate of the TEMPO-/TEMPO+ couple (TEMPO = 2,2,6,6-tetramethyl1-piperidinyloxy radical) Part I. ESR-linebroadening measurements at $\mathrm{T}=298 \mathrm{~K}$, Phys. Chem. Chem. Phys. 4 (22) (2002) 5546-5549.

[219] J. C. Jernigan, N. A. Surridge, M. E. Zvanut, M. Silver, R. W. Murray, Electricalfield-driven electron self-exchange in a mixed-valent osmium(II/III) bipyridine polymer: solid-state reactions of low exothermicity, J. Phys. Chem. 93 (11) (1989) 4620-4627.

[220] R. Pyati, R. W. Murray, Solvent Dynamics Effects on Heterogeneous Electron Transfer Rate Constants of Cobalt Tris(bipyridine), J. Am. Chem. Soc. 118 (7) (1996) 1743-1749.

[221] M. H. Chisholm, K. C. Glasgow, L. J. Klein, A. M. Macintosh, D. G. Peters, Heterogeneous Electron-Transfer Rate Constants for M2(O2CR)40/+, Where $\mathrm{M}=\mathrm{Mo}, \mathrm{W}, \mathrm{Ru}$, or Rh and R = Alkyl or Aryl, Inorg. Chem. 39 (19) (2000) 4354-4357.

[222] P. Arora, R. E. White, M. Doyle, Capacity Fade Mechanisms and Side Reactions in Lithium-Ion Batteries, J. Electrochem. Soc. 145 (10) (1998) 3647-3667.

[223] L. Bugnon, C. J. H. Morton, P. Novak, J. Vetter, P. Nesvadba, Synthesis of Poly(4-methyacryloyloxy-TEMPO) via Group-Transfer Polymerization and Its Evaluation in Organic Radical Battery, Chem. Mater. 19 (2007) 2910-2914.

[224] T. Ibe, R. B. Frings, A. Lachowicz, S. Kyo, H. Nishide, Nitroxide polymer networks formed by Michael addition: on site-cured electrode-active organic coating, Chem. Commun. 46 (2010) 3475-3477.

[225] T. Suga, M. T. Hunley, T. E. Long, H. Nishide, Electronspinning of radical polymers: redox-active fibrous membrane formation, Polym. J. 44 (2012) 264 268.

[226] T. Sukegawa, K. Sato, K. Oyaizu, H. Nishide, Efficient charge transport of a radical polyether / SWCNT composite electrode for an organic radical battery with high charge-storage density, RSC Adv. 5 (2015) 15448-15452. 
[227] H.-C. Lin, C.-C. Li, J.-T. Lee, Nitroxide polymer brushes grafted onto silica nanoparticles as cathodes for organic radical batteries, J. Power Sources 196 (19) (2011) 8098-8103.

[228] A. A. Golriz, T. Kaule, M. B. Untch, K. Kolman, R. Berger, J. S. Gutmann, Redox Active Polymer Brushes with Phenothiazine Moieties, ACS Appl. Mater. Interfaces 5 (7) (2013) 2485-2494.

[229] T. Sukegawa, I. Masuko, K. Oyaizu, H. Nishide, Expanding the Dimensionality of Polymers Populated with Organic Robust Radicals toward Flow Cell Application: Synthesis of TEMPO-Crowded Bottlebrush Polymers Using Anionic Polymerization and ROMP, Macromolecules 47 (24) (2014) 8611-8617.

[230] J. Kim, J. Kim, J. Lee, H.-K. Song, C. Yang, Synthesis of a Redox-Active Denpol as a Potential Electrode in Rechargeable Organic Batteries, ChemElectroChem 1 (10) (2014) 1618-1622.

[231] Y.-H. Wang, M.-K. Hung, C.-H. Lin, H.-C. Lin, J.-T. Lee, Patterned nitroxide polymer brushes for thin-film cathodes in organic radical batteries, Chem. Commun. 47 (4) (2011) 1249-1251.

[232] M.-K. Hung, Y.-H. Wang, C.-H. Lin, H.-C. Lin, J.-T. Lee, Synthesis and electrochemical behaviour of nitroxide polymer brush thin-film electrodes for organic radical batteries, J. Mater. Chem. 22 (4) (2012) 1570-1577.

[233] Y. Kim, C. Jo, J. Lee, C. W. Lee, S. Yoon, An ordered nanocomposite of organic radical polymer and mesocellular carbon foam as cathode material in lithium ion batteries, J. Mater. Chem. 22 (4) (2012) 1453-1458.

[234] C. R. DeBlase, K. E. Silberstein, T.-T. Truong, H. D. Abruña, W. R. Dichtel, $\beta$ Ketoenamine-Linked Covalent Organic Frameworks Capable of Pseudocapacitive Energy Storage, J. Am. Chem. Soc. 135 (45) (2013) 16821-16824.

[235] A. Morozan, F. Jaouen, Metal organic frameworks for electrochemical applications, Energy Environ. Sci. 5 (2012) 9269-9290.

[236] C.-H. Lin, W.-J. Chou, J.-T. Lee, Three-Dimesionally Ordered Macroporous Nitroxide Polymer Brush Electrodes Prepared by Surface-Initiated Atom Transfer Polymerization for Organic Radical Batteries, Macromol. Rapid Commun. 33 (2012) 107-113.

[237] Y. Takahashi, N. Hayashi, K. Oyaizu, K. Honda, H. Nishide, Totally Organic Polymer-Based Electrochromic Cell Using TEMPO-Substituted Polynorbornene as a Counter Electrode-Active Material, Polymer J. 40 (8) (2008) 763-767.

[238] C. Ponce de Leon, A. Frias-Ferrer, J. Gonzalez-Garcia, D. A. Szanto, F. C. Walsh, Redox flow cells for energy conversion, J. Power Sources 160 (1) (2006) 716-732.

[239] M. Skyllas-Kazacos, M. H. Chakrabarti, S. A. Hajimolana, F. S. Mjalli, M. Saleem, Progress in Flow Battery Research and Development, J. Electrochem. Soc. 158 (8) (2011) R55-R79.

[240] A. Z. Weber, M. M. Mench, J. P. Meyers, P. N. Ross, J. T. Gostick, Q. Liu, Redox flow batteries: a review, J. Appl. Electrochem. 41 (10) (2011) 1137-1164.

[241] W. Wang, Q. Luo, B. Li, X. Wei, L. Li, Z. Yang, Recent Progress in Redox Flow Battery Research and Development, Adv. Funct. Mater. 23 (8) (2013) 970-986.

[242] B. Chalamala, T. Soundappan, G. Fisher, M. Anstey, V. Viswanathan, M. Perry, Redox Flow Batteries: An Engineering Perspective, Proceedings of the IEEE 
102 (6) (2014) 976-999.

[243] G. L. Soloveichik, Flow Batteries: Current Status and Trends, Chem. Rev. 115 (20) (2015) 11533-11558.

[244] M. Park, J. Ryu, W. Wang, J. Cho, Material design and engineering of nextgeneration flow-battery technologies, Nat. Rev. Mater. 2 (2016) 16080.

[245] R. M. Darling, K. G. Gallagher, J. A. Kowalski, S. Ha, F. R. Brushett, Pathways to low-cost electrochemical energy storage: a comparison of aqueous and nonaqueous flow batteries, Energy Environ. Sci. 7 (2014) 3459-3477.

[246] R. Dmello, J. D. Milshtein, F. R. Brushett, K. C. Smith, Cost-driven materials selection criteria for redox flow battery electrolytes, J. Power Sources 330 (2016) $261-272$.

[247] Y. Xu, Y. Wen, J. Cheng, G. Cao, Y. Yang, Study on a single flow acid Cdchloranil battery, Electrochem. Commun. 11 (7) (2009) 1422-1424.

[248] Y. Xu, Y.-H. Wen, J. Cheng, G.-P. Cao, Y.-S. Yang, A study of tiron in aqueous solutions for redox flow battery application, Electrochim. Acta 55 (3) (2010) 715-720.

[249] S. Nawar, B. Huskinson, M. Aziz, Benzoquinone-Hydroquinone Couple for Flow Battery, in: Symposium C-Electrocatalysis and Interfacial Electrochemistry for Energy Conversion and Storage, vol. 1491 of MRS Proceedings, 2013.

[250] B. Huskinson, S. Nawar, M. R. Gerhardt, M. J. Aziz, Novel Quinone-Based Couples for Flow Batteries, ECS Trans. 53 (7) (2013) 101-105.

[251] B. Yang, L. Hoober-Burkhardt, F. Wang, G. K. Surya Prakash, S. R. Narayanan, An Inexpensive Aqueous Flow Battery for Large-Scale Electrical Energy Storage Based on Water-Soluble Organic Redox Couples, J. Electrochem. Soc. 161 (9) (2014) A1371-A1380.

[252] S. Er, C. Suh, M. P. Marshak, A. Aspuru-Guzik, Computational design of molecules for an all-quinone redox flow battery, Chem. Sci. 6 (2015) 885-893.

[253] X. Li, Modeling and simulation study of a metal free organic-inorganic aqueous flow battery with flow through electrode, Electrochim. Acta 170 (2015) 98-109.

[254] B. Huskinson, M. P. Marshak, C. Suh, S. Er, M. R. Gerhardt, C. J. Galvin, X. Chen, A. Aspuru-Guzik, R. G. Gordon, M. J. Aziz, A metal-free organicinorganic aqueous flow battery, Nature 505 (7482) (2014) 195-198.

[255] X. Wei, W. Xu, M. Vijayakumar, L. Cosimbescu, T. Liu, V. Sprenkle, W. Wang, TEMPO-Based Catholyte for High-Energy Density Nonaqueous Redox Flow Batteries, Adv. Mat. 26 (45) (2014) 7649-7653.

[256] K. Takechi, Y. Kato, Y. Hase, A Highly Concentrated Catholyte Based on a Solvate Ionic Liquid for Rechargeable Flow Batteries, Advanced Materials 27 (15) (2015) 2501-2506.

[257] C. Buhrmester, L. Moshurchak, R. L. Wang, J. R. Dahn, Phenothiazine Molecules: Possible Redox Shuttle Additives for Chemical Overcharge and Overdischarge Protection for Lithium-Ion Batteries, J. Electrochem. Soc. 153 (2) (2006) A288A294.

[258] A. P. Kaur, N. E. Holubowitch, S. Ergun, C. F. Elliott, S. A. Odom, A Highly Soluble Organic Catholyte for Non-Aqueous Redox Flow Batteries, Energy Technology 3 (5) (2015) 476-480. 
[259] J. R. Dahn, J. Jiang, L. M. Moshurchak, M. D. Fleischauer, C. Buhrmester, L. J. Krausec, High-Rate Overcharge Protection of LiFePO4-Based Li-Ion Cells Using the Redox Shuttle Additive 2,5-Ditertbutyl-1,4-dimethoxybenzene, J. Electrochem. Soc. 152 (6) (2005) A1283-A1289.

[260] J. Huang, L. Cheng, R. S. Assary, P. Wang, Z. Xue, A. K. Burrell, L. A. Curtiss, L. Zhang, Liquid Catholyte Molecules for Nonaqueous Redox Flow Batteries, Adv. Energy Mat. 5 (6) (2015) 1401782.

[261] J. Winsberg, T. Hagemann, S. Muench, C. Friebe, B. Häupler, T. Janoschka, S. Morgenstern, M. D. Hager, U. S. Schubert, Poly(boron-dipyrromethene)-A Redox-Active Polymer Class for Polymer Redox-Flow Batteries, Chem. Mater. 28 (10) (2016) 3401-3405.

[262] J. Winsberg, S. Muench, T. Hagemann, S. Morgenstern, T. Janoschka, M. Billing, F. H. Schacher, G. Hauffman, J.-F. Gohy, S. Hoeppener, M. D. Hager, U. S. Schubert, Polymer/zinc hybrid-flow battery using block copolymer micelles featuring a TEMPO corona as catholyte, Polym. Chem. 7 (9) (2016) 1711-1718.

[263] J. Winsberg, T. Janoschka, S. Morgenstern, T. Hagemann, S. Muench, G. Hauffman, J.-F. Gohy, M. D. Hager, U. S. Schubert, Poly(TEMPO)/Zinc Hybrid-Flow Battery: A Novel, "Green," High Voltage, and Safe Energy Storage System, Adv. Mater. 28 (11) (2016) 2238-2243, doi:Lbibinfo \{doi\}\{10.1002/adma.201505000\}.

[264] G. Nagarjuna, J. Hui, K. J. Cheng, T. Lichtenstein, M. Shen, J. S. Moore, J. Rodríguez-López, Impact of Redox-Active Polymer Molecular Weight on the Electrochemical Properties and Transport Across Porous Separators in Nonaqueous Solvents, J. Am. Chem. Soc. 136 (46) (2014) 16309-16316.

[265] M. Burgess, J. S. Moore, J. Rodríguez-López, Redox Active Polymers as Soluble Nanomaterials for Energy Storage, Acc. Chem. Res. 49 (11) (2016) 2649-2657.

[266] H. Chen, M. Armand, G. Demailly, F. Dolhem, P. Poizot, J.-M. Tarascon, From Biomass to a Renewable $\mathrm{Li}_{X} \mathrm{C}_{6} \mathrm{O}_{6}$ Organic Electrode for Sustainable Li-Ion Batteries, ChemSusChem 1 (4) (2008) 348-355.

[267] R. H. Zeng, X. P. Li, Y. C. Qiu, W. S. Li, J. Yi, D. S. Lu, C. L. Tan, M. Q. $\mathrm{Xu}$, Synthesis and properties of a lithium-organic coordination compound as lithium-inserted material for lithium ion batteries, Electrochem. Commun. 12 (9) (2010) 1253-1256.

[268] X. Han, C. Chang, L. Yuan, T. Sun, J. Sun, Aromatic Carbonyl Derivative Polymers as High-Performance Li-Ion Storage Materials, Adv. Mater. 19 (12) (2007) 1616-1621.

[269] D.-H. Seo, H. Kim, H. Kim, W. A. Goddard, K. Kang, The predicted crystal structure of $\mathrm{Li}_{4} \mathrm{C}_{6} \mathrm{O}_{6}$, an organic cathode material for Li-ion batteries, from first-principles multi-level computational methods, Energy Environ. Sci. 4 (2011) 4938-4941.

[270] D. Zhang, H. Lan, Y. Li, The application of a non-aqueous bis(acetylacetone)ethylenediamine cobalt electrolyte in redox flow battery, J. Power Sources 217 (2012) 199-203.

[271] D. Aurbach, E. Zinigrad, H. Teller, P. Dan, Factors Which Limit the Cycle Life of Rechargeable Lithium (Metal) Batteries, J. Electrochem. Soc. 147 (4) (2000) 1274-1279. 
[272] D. Aurbach, E. Zinigrad, H. Teller, Y. Cohen, G. Salitra, H. Yamin, P. Dan, E. Elster, Attempts to Improve the Behavior of Li Electrodes in Rechargeable Lithium Batteries, J. Electrochem. Soc. 149 (10) (2002) A1267-A1277.

[273] C. M. López, J. T. Vaughey, D. W. Dees, Morphological Transitions on Lithium Metal Anodes, J. Electrochem. Soc. 156 (9) (2009) A726-A729.

[274] C. M. López, J. T. Vaughey, D. W. Dees, Insights into the Role of Interphasial Morphology on the Electrochemical Performance of Lithium Electrodes, J. Electrochem. Soc. 159 (6) (2012) A873-A886.

[275] S. Neuhold, D. J. Schroeder, J. T. Vaughey, Effect of surface preparation and R-group size on the stabilization of lithium metal anodes with silanes, J. Power Sources 206 (2012) 295-300.

[276] Y. Lu, S. K. Das, S. S. Moganty, L. A. Archer, Ionic Liquid-Nanoparticle Hybrid Electrolytes and their Application in Secondary Lithium-Metal Batteries, Adv. Mater. 24 (32) (2012) 4430-4435.

[277] H. Sano, H. Sakaebe, H. Matsumoto, Effect of Organic Additives on Electrochemical Properties of Li Anode in Room Temperature Ionic Liquid, J. Electrochem. Soc. 158 (3) (2011) A316-A321.

[278] J. Feng, X. Ai, Y. Cao, H. Yang, A highly soluble dimethoxybenzene derivative as a redox shuttle for overcharge protection of secondary lithium batteries, Electrochem. Commun. 9 (1) (2007) 25-30.

[279] S. H. Oh, C.-W. Lee, D. H. Chun, J.-D. Jeon, J. Shim, K. H. Shin, J. H. Yang, A metal-free and all-organic redox flow battery with polythiophene as the electroactive species, J. Mater. Chem. A 2 (2014) 19994-19998.

[280] H. Zhang, M.-Y. Chow, Comprehensive dynamic battery modeling for PHEV applications, in: Power and Energy Society General Meeting, IEEE, 1-6, 2010.

[281] R. E. Garcia, Y.-M. Chiang, W. Craig Carter, P. Limthongkul, C. M. Bishop, Microstructural Modeling and Design of Rechargeable Lithium-Ion Batteries, J. Electrochem. Soc. 152 (1) (2005) A255-A263.

[282] W. A. Braff, M. Z. Bazant, C. R. Buie, Membrane-less hydrogen bromine flow battery, Nat. Commun. 4 (2013) 2346.

[283] Materials Project, "https://materialsproject.org/" Accessed: Nov. 2013, Tech. Rep., 2013.

[284] G. G. Rodríguez-Calero, M. A. Lowe, Y. Kiya, H. D. Abruña, Electrochemical and Computational Studies on the Electrocatalytic Effect of Conducting Polymers toward the Redox Reactions of Thiadiazole-Based Thiolate Compounds, J. Phys. Chem. C 114 (13) (2010) 6169-6176.

[285] S. E. Burkhardt, M. A. Lowe, S. Conte, W. Zhou, H. Qian, G. G. RodriguezCalero, J. Gao, R. G. Hennig, H. D. Abruña, Tailored redox functionality of small organics for pseudocapacitive electrodes, Energy Environ. Sci. 5 (2012) 7176-7187.

[286] S. E. Burkhardt, J. Bois, J.-M. Tarascon, R. G. Hennig, H. D. Abruña, LiCarboxylate Anode Structure-Property Relationships from Molecular Modeling, Chem. Mater. 25 (2) (2013) 132-141. 